\title{
Candidate genes for alcohol preference identified by expression profiling in alcohol-preferring and -nonpreferring reciprocal congenic rats
}

Tiebing Liang ${ }^{1 *}$, Mark W Kimpel ${ }^{2}$, Jeanette N McClintick ${ }^{3}$, Ashley R Skillman ${ }^{1}$, Kevin McCall ${ }^{4}$, Howard J Edenberg ${ }^{3}$, Lucinda G Carr ${ }^{1}$

\begin{abstract}
Background: Selectively bred alcohol-preferring (P) and alcohol-nonpreferring (NP) rats differ greatly in alcohol preference, in part due to a highly significant quantitative trait locus (QTL) on chromosome 4. Alcohol consumption scores of reciprocal chromosome 4 congenic strains NP.P and P.NP correlated with the introgressed interval. The goal of this study was to identify candidate genes that may influence alcohol consumption by comparing gene expression in five brain regions of alcohol-naïve inbred alcohol-preferring and P.NP congenic rats: amygdala, nucleus accumbens, hippocampus, caudate putamen, and frontal cortex.
\end{abstract}

Results: Within the QTL region, 104 cis-regulated probe sets were differentially expressed in more than one region, and an additional 53 were differentially expressed in a single region. Fewer trans-regulated probe sets were detected, and most differed in only one region. Analysis of the average expression values across the 5 brain regions yielded 141 differentially expressed cis-regulated probe sets and 206 trans-regulated probe sets. Comparing the present results from inbred alcohol-preferring vs. congenic P.NP rats to earlier results from the reciprocal congenic NP.P vs. inbred alcohol-nonpreferring rats demonstrated that 74 cis-regulated probe sets were differentially expressed in the same direction and with a consistent magnitude of difference in at least one brain region.

Conclusions: Cis-regulated candidate genes for alcohol consumption that lie within the chromosome 4 QTL were identified and confirmed by consistent results in two independent experiments with reciprocal congenic rats. These genes are strong candidates for affecting alcohol preference in the inbred alcohol-preferring and inbred alcohol-nonpreferring rats.

\section{Background}

Alcoholism has a substantial genetic component, with estimates of heritability ranging from 50 to $60 \%$ for both men and women [1-3]. The associations of several genes with risk for alcoholism have been replicated in human studies: GABRA2 [4-11], ADH4 [12-14], and CHRM2 [15,16]. Several other genes have been associated with alcoholism or related traits and await replication [17,18], including TAS2R16 [19,20], NTRK2 [21], GABRG3 [22], GABRA1 [23], OPRK1 and PDYN [24,25], NFKB1 [26], ANKK1 [27], ACN9 [28], TACR3

\footnotetext{
* Correspondence: tliang@iupui.edu

'Indiana University School of Medicine, Department of Medicine, IB424G, 975 West Walnut Street, Indianapolis, IN 46202, USA
}

[29], CHRNA5 [30], SNCA [31], NPY [32,33], and NPY receptors [34].

Selected strains of rodents that differ in voluntary alcohol consumption have been valuable tools to aid in dissecting the genetic components of alcoholism [35-38]. The alcohol-preferring (P) and -nonpreferring (NP) rat lines were developed through bi-directional selective breeding from a randomly bred, closed colony of Wistar rats on the basis of alcohol preference in a two-bottle choice paradigm [36]. P rats display the phenotypic characteristics considered necessary for an animal model of alcoholism [39,40]. Subsequently, inbred alcohol-preferring (iP) and -nonpreferring (iNP) strains were established; these inbred strains maintain highly divergent alcohol consumption scores [41]. Due to the

\section{() Biomed Central}


physiological and genetic similarity between humans and rats, iP and iNP rats can be studied to identify important genetic factors that might influence predisposition to alcoholism in humans.

A highly significant quantitative trait locus (QTL) that influenced alcohol preference was identified on chromosome 4, with a maximum LOD score of 9.2 in a cross between iP and iNP rats [41]. The chromosome 4 QTL acts in an additive fashion and accounts for approximately $11 \%$ of the phenotypic variability. This approximately 100 million bases (Mb) QTL region is likely to harbor genes that directly contribute to alcohol preference. Several candidate genes identified in human studies (SNCA, NPY, CHRM2, TAS2R16, and ACN9) have homologs located within this rat chromosome 4 QTL. Snca and Npy have been shown to be differentially expressed between these two strains [42,43].

Reciprocal congenic strains (Figure 1) in which the iP chromosome 4. QTL interval was transferred to the iNP (NP.P-(D4Rat119-D4Rat55) and the iNP chromosome 4 QTL interval was transferred to the iP (P.NP(D4Rat119-D4Rat55) exhibited the expected effect on alcohol consumption: that is, the consumption correlated with the strain that donated the chromosome 4 QTL interval [44]. (In this paper, the reciprocal congenic strains will be referred to as NP.P and P.NP.) Thus, the chromosome $4 \mathrm{QTL}$ region is, in part, responsible for the disparate alcohol consumption observed between the iP and iNP rats.

Identifying the genes in the chromosome 4 interval that underlie the phenotype has been difficult. We adopted a strategy of using transcriptome analysis to determine which genes are altered in expression in the congenic strains; this is a powerful approach toward gene identification [45-47]. Using this approach reduces the 'noise' from unrelated differences in gene expression, because the two strains are identical except for the QTL sequences, and thereby increases the specificity with which genes contributing to the specific phenotype can be detected.

Previous transcriptome profiling of the NP.P congenic strain and the iNP background strain identified 35 candidate genes in the chromosome 4 QTL that were cisregulated in at least one of the five brain regions studied [47]. Nucleus accumbens, frontal cortex, amygdala, hippocampus, and caudate putamen were examined, based on their inclusion in the mesolimbic and mesocortical systems, both of which are important in the initiation and maintenance of goal-directed and reward-mediated behaviors $[48,49]$. In the present paper, we compare the iP background strain with the reciprocal congenic strain (P.NP) to identify cis and trans differentially expressed genes. The strategy of identifying differentially expressed genes in congenic strains and using comparisons

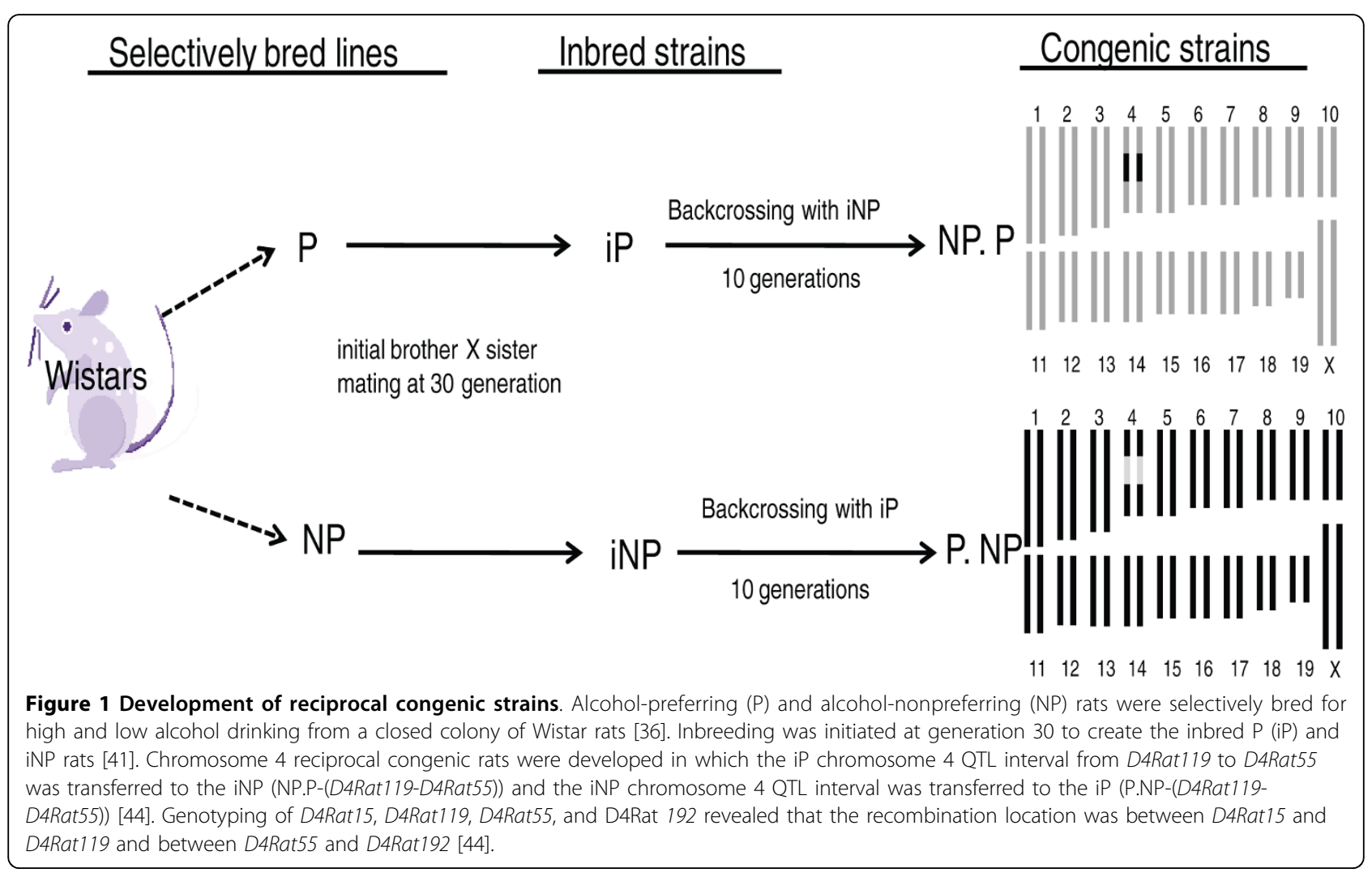


between the reciprocal congenic strains to further support the differences allowed us to identify genes that are strong candidates for affecting alcohol preference.

\section{Results}

\section{Cis-regulated genes}

Because alcohol preference in the congenic strains correlated with the strain origin of the introgressed region, our primary hypothesis was that the genes in that region contributing to the phenotype would differ in expression as a result of cis-acting elements. Transcriptome analyses were performed to detect differences in gene expression between iP and congenic P.NP rats in five brain regions: nucleus accumbens, frontal cortex, amygdala, hippocampus, and caudate putamen.

Of the probe sets differentially expressed in the introgressed region of chromosome 4, many are located within the 95\% confidence interval of the QTL (54.8 to $105 \mathrm{Mb}$ ). (Figure 2) The number of differentially expressed probe sets (false discovery rate $(\mathrm{FDR}) \leq 0.25$ ) within the QTL was similar in each of the 5 brain regions, ranging from 72 in the nucleus accumbens to 89 in the hippocampus (Table 1). most probe sets significant in any one brain region were significant in multiple regions; 104 of the 157 cis-regulated probe sets showed differential expression in more than one brain

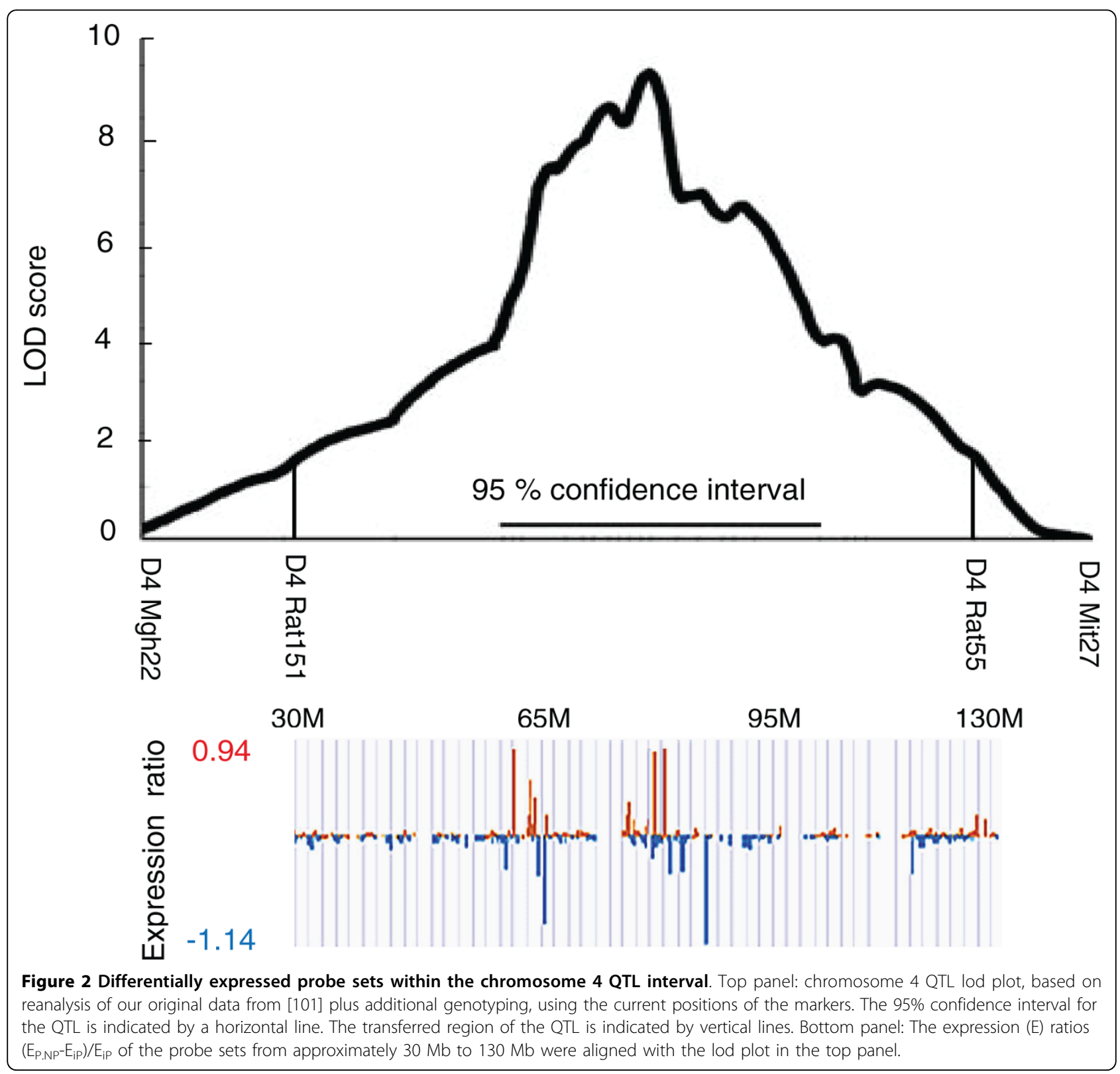


Table 1 Number of differentially expressed probe sets in the iP vs P.NP Comparison

\begin{tabular}{|c|c|c|c|c|c|c|c|c|}
\hline & $\begin{array}{c}\text { Nucleus } \\
\text { accumbens }\end{array}$ & Amygdala & $\begin{array}{l}\text { Frontal } \\
\text { cortex }\end{array}$ & $\begin{array}{l}\text { Hippo- } \\
\text { campus }\end{array}$ & $\begin{array}{l}\text { Caudate } \\
\text { putamen }\end{array}$ & $\begin{array}{l}\text { At least one } \\
\text { brain region }\end{array}$ & $\begin{array}{l}\text { Multiple brain } \\
\text { regions }\end{array}$ & $\begin{array}{c}\text { Combined } \\
\text { regions }\end{array}$ \\
\hline \multicolumn{9}{|l|}{$\begin{array}{l}\text { Significant cis-regulated } \\
\text { probe sets }\end{array}$} \\
\hline Total & 72 & 74 & 78 & 89 & 82 & 157 & 104 & 141 \\
\hline $\begin{array}{l}\text { Single brain region } \\
\text { only }\end{array}$ & 11 & 8 & 7 & 10 & 17 & & & \\
\hline $\begin{array}{l}\text { Only significant in } \\
\text { combined }\end{array}$ & & & & & & & & 19 \\
\hline \multicolumn{9}{|l|}{$\begin{array}{l}\text { Significant trans- } \\
\text { regulated probe sets }\end{array}$} \\
\hline Total & 14 & 7 & 16 & 17 & 54 & 85 & 10 & 206 \\
\hline $\begin{array}{l}\text { Single brain region } \\
\text { only }\end{array}$ & 9 & 2 & 8 & 10 & 46 & & & \\
\hline $\begin{array}{l}\text { Only significant in } \\
\text { combined }\end{array}$ & & & & & & & & 143 \\
\hline
\end{tabular}

Cis-regulated probe sets are those located in the chromosome 4 QTL interval; trans-regulated probe sets are located in the remainder of the genome. The first five columns show the number of cis- and trans-regulated probe sets that differ between iP and P.NP in each individual brain region. 'At least one brain region' shows the total number of unique probe sets that differed in one or more regions. 'Multiple brain regions' shows the total number of unique probe sets that differed in at least two of the five brain regions. 'Average expression' shows probe sets that differ when the average expression across the five regions in each animal was analyzed. 'Single brain region only' shows the number of unique probe sets significant in only that brain region. 'In average only' shows unique probe sets that were significant only in analysis of the average level of expression across the five regions in each animal.

region. Only 8 to $21 \%$ of those detected in any single region were detected in only that region (Table 1). Analysis of the average level of gene expression across all 5 regions showed 141 probe sets that significantly differed between the strains; this included 19 probe sets not detected in any of the individual regions (Table 1; also see Table S1 in Additional file 1, which includes a list of significant differentially expressed cis-regulated genes).

\section{Trans-regulated genes}

To detect trans-regulated genes (genes identical in the two strains that are differentially expressed due to variations in a regulatory gene located within the chromosome 4 region), the remainder of the genome (everything except the chromosome 4 QTL region) was analyzed. Differentially expressed genes are not concentrated on any chromosome, other than chromosome 4 (Table S2 in Additional file 1). Although the total number of genome probe sets analyzed was much greater than the QTL probe sets (for example, 23,050 probe sets were used in the averaged analysis, versus 960 in the cis-analysis above; see Materials and methods for details), fewer trans-regulated probe sets were differentially expressed in each region or in multiple regions (Table 1). Unexpectedly, we found 54 significant probe sets in the caudate putamen, of which 46 were only significant in that brain region. The analysis of the average level of gene expression across all 5 regions was more powerful than the analyses of individual brain regions; 206 trans-regulated probe sets differed, including 143 that did not differ in any individual region (Table 1; also see Table S2 in Additional file 1, which includes a list of differentially expressed trans-regulated genes).

Some of the trans-regulated genes were previously implicated in drug or alcohol addiction, including Pnlip (pancreatic lipase) [50], Homer1 (homer homolog 1 (Drosophila)) [51], Jun (Jun oncogene), Adhfe1 (alcohol dehydrogenase, iron containing, 1) [52], Ptprr (protein tyrosine phosphatase, receptor type, R) [53], Klf15 (Kruppel-like factor 15) [54,55], Nfkb1 (nuclear factor of kappa light polypeptide gene enhancer in B-cells 1) [26], Sox18 (SRY-box containing gene 18) [56,57], and Qdpr (quinoid dihydropteridine reductase) [58,59].

\section{Confirmation by quantitative RT-PCR}

To confirm some of the genes that differed in expression between the iP and P.NP, quantitative RT-PCR (qRT-PCR) was performed using RNA samples of the brain regions. Ten genes were selected based on literature reports of their possible involvement in pathways related to alcohol seeking behavior (Table 2). Among the 44 comparisons with genes that significantly differed on microarrays, 35 (79\%) were differentially expressed in the same direction when tested by qRT-PCR.

\section{Comparison of reciprocal congenic strains}

Previously published data comparing expression in NP.P versus iNP congenics [47] were compared to the present data (iP versus P.NP) to identify probe sets that exhibited consistent expression differences between the two experiments. For both experiments we calculated the ratio of expression from the animals carrying the iP 
Table 2 Quantitative RT-PCR confirmation

\begin{tabular}{|c|c|c|c|c|c|c|c|c|c|c|c|}
\hline \multirow[b]{3}{*}{$\begin{array}{l}\text { Affymetrix } \\
\text { ID }\end{array}$} & \multirow[b]{3}{*}{$\begin{array}{l}\text { Gene } \\
\text { symbol }\end{array}$} & \multicolumn{10}{|c|}{ Ratio of expression (iP vs P.NP) ${ }^{a}$} \\
\hline & & \multicolumn{2}{|c|}{ Nucleus accumbens } & \multicolumn{2}{|c|}{ Amygdala } & \multicolumn{2}{|c|}{ Frontal cortex } & \multicolumn{2}{|c|}{ Hippocampus } & \multicolumn{2}{|c|}{ Caudate putamen } \\
\hline & & Microarray & $\begin{array}{l}\text { qRT- } \\
\text { PCR }\end{array}$ & Microarray & $\begin{array}{l}\text { qRT- } \\
\text { PCR }\end{array}$ & Microarray & $\begin{array}{l}\text { qRT- } \\
\text { PCR }\end{array}$ & Microarray & $\begin{array}{l}\text { qRT- } \\
\text { PCR }\end{array}$ & Microarray & $\begin{array}{l}\text { qRT- } \\
\text { PCR }\end{array}$ \\
\hline 1368358_a_at & Ptprr & 2.22 & 2.28 & 2.47 & 2.71 & 2.17 & 1.85 & 2.42 & 2.77 & 1.98 & 2.28 \\
\hline 1395714_at & Copg2 IT & -3.97 & -2.45 & -28.29 & -1.73 & -31.36 & -1.61 & -4.57 & -2.12 & -20.13 & -1.23 \\
\hline 1394939_at & Ppmlk & -2.05 & 1.30 & -1.74 & -1.62 & -2.79 & -2.54 & -1.86 & -3.12 & -2.39 & -2.49 \\
\hline 1379275_at & $\operatorname{Sn} \times 10$ & 1.67 & -1.16 & 2.18 & 1.68 & 1.94 & 1.15 & 1.69 & 2.42 & 2.02 & 1.64 \\
\hline 1380094_a_at & Zfp212 & 1.30 & 1.54 & 1.22 & -1.04 & 1.21 & 1.19 & 1.28 & 1.58 & 1.43 & 1.86 \\
\hline 1367734_at & Akribl & 1.22 & 1.13 & 1.12 & 1.30 & 1.27 & 1.58 & 1.16 & 1.06 & 1.25 & 1.15 \\
\hline 1379480_at & Dgki & 1.23 & 2.72 & 1.13 & -1.26 & 1.17 & -2.97 & 1.26 & 1.11 & 1.25 & -1.71 \\
\hline 1370007_at & Pdia4 & 1.24 & 1.57 & 1.34 & -1.01 & {$[1.14]$} & 1.05 & & & 1.36 & -1.13 \\
\hline 1367977_at & Snca & & & & & -1.11 & -1.22 & {$[1.07]$} & 1.05 & -1.12 & -1.09 \\
\hline 1387154_at & Npy & & & & & {$[-1.11]$} & 1.01 & & & {$[-1.08]$} & -1.20 \\
\hline
\end{tabular}

${ }^{\mathrm{a}} \mathrm{A}$ positive number indicates the ratio of the expression level of iP/P.NP; a negative number indicates the ratio of expression level of P.NP/iP. Bold numbers in the microarray columns indicate expression is significantly different at FDR $<0.05$; square brackets indicate FDR between 0.05 and 0.25 . qRT-PCR value is an average of six technical replicates.

QTL region to that from the animals carrying the iNP QTL region (that is, NP.P/iNP and iP/P.NP). Because the earlier experiment was less powerful (comparing only six animals from each strain) and because we could use the consistency of results from the two experiments to filter out false positives, we relaxed the level of significance to $P \leq 0.05$ for this comparison to reduce false negatives. Any false positives introduced by this relaxation should not be consistent between the two independent experiments. A total of 74 probesets that were significant in the two experiments (at $P \leq 0.05$ ) in the same brain region or in the average of the brain regions and with consistent direction in both experiments were identified (Table 3). Additional robust multi-chip average (RMA) data and uncorrected $P$-value data are included (Table S3 in Additional file 1). All of the reproducible probe sets were located within the chromosome 4 QTL interval, and therefore cis-regulated. The expression differences of these 74 cis-regulated genes were highly correlated in the two experiments $\left(R^{2}\right.$ $=0.88$; Figure 3 ); 71 showed expression differences of similar amounts in the same direction in both experiments. Thus, these cis-regulated genes are strong candidates for affecting alcohol preference. Even though the iP versus P.NP comparison identified 85 significant trans-regulated probe sets in at least one brain region and 206 significant probe sets when the data from all 5 regions was averaged (FDR $\leq 0.25$; Table 1 ), no transregulated probe set was common to both experiments.

\section{Discussion}

In this study, the iP background strain was compared to the P.NP congenic strain, which has the iNP chromosome 4. QTL interval between markers D4Rat119 and D4Rat55 introgressed onto the iP background. Because the congenic and background strains are identical except for the region on chromosome 4 , the a priori expectation is that only cis-regulated genes located in that region of chromosome 4 or genes trans-regulated by genes within that region should differ. This is expected to be a small set of genes, the signal from which could be masked by random variations in the very large set of genes that do not differ. Among cis-regulated differentially expressed probe sets, only 53 out of 157 were significant in a single brain region. Among the other 104 probe sets, 102 differed in the same direction in at least two regions. Many genes are expected to be expressed under similar regulatory control in different brain regions, so we also conducted an analysis of the average expression levels across the five regions and identified additional genes. The magnitude of the differences was small. Other comparisons of gene expression in rat brain have also reported small differences [47,58,60-62].

These findings from the iP versus P.NP congenic strain were then compared with previous transcriptome profiling of the reciprocal NP.P congenic strain versus iNP background strain [47]. We identified 74 cis-regulated probe sets with consistent direction and magnitude of expression differences in the two experiments (Figure 3; Table 3). These are strong candidates for influencing the alcohol preference phenotype. The differences in gene expression, although small, were quite consistent between experiments for these cis-regulated genes (Table 3, Figure 3). This is noteworthy since the experiments were completely independent, done at two different times using different strains (NP.P versus iNP and iP versus P.NP) bred at different times, and demonstrates the reproducibility of transcriptome profiling on microarrays. 


\begin{tabular}{|c|c|c|c|c|c|c|c|c|c|c|c|c|c|c|}
\hline \multirow[b]{3}{*}{ Probe set } & \multirow[b]{3}{*}{ Symbol } & \multirow[b]{3}{*}{ Gene title } & \multicolumn{12}{|c|}{ Ratio of expression (iP vs P.NP and NP.P vs iNP) ${ }^{a}$} \\
\hline & & & \multicolumn{2}{|c|}{ Amygdala } & \multicolumn{2}{|c|}{$\begin{array}{l}\text { Nucleus } \\
\text { accumbens }\end{array}$} & \multicolumn{2}{|c|}{$\begin{array}{l}\text { Frontal } \\
\text { cortex }\end{array}$} & \multicolumn{2}{|c|}{ Hippocampus } & \multicolumn{2}{|c|}{$\begin{array}{l}\text { Caudate } \\
\text { putamen }\end{array}$} & \multicolumn{2}{|c|}{$\begin{array}{l}\text { Combined } \\
\text { regions }\end{array}$} \\
\hline & & & $\begin{array}{l}\text { iP } \\
\text { vs. } \\
\text { P.NP } \\
\end{array}$ & $\begin{array}{c}\text { NP.P } \\
\text { vs. } \\
\text { iNP } \\
\end{array}$ & $\begin{array}{c}\text { iP } \\
\text { vs. } \\
\text { P.NP } \\
\end{array}$ & $\begin{array}{l}\text { NP.P } \\
\text { Vs. } \\
\text { iNP }\end{array}$ & $\begin{array}{l}\text { iP } \\
\text { vs. } \\
\text { P.NP }\end{array}$ & $\begin{array}{c}\text { NP.P } \\
\text { vs. } \\
\text { iNP } \\
\end{array}$ & $\begin{array}{c}\text { iP } \\
\text { vs. } \\
\text { P.NP } \\
\end{array}$ & $\begin{array}{c}\text { NP.P } \\
\text { vs. iNP }\end{array}$ & $\begin{array}{l}\text { iP } \\
\text { vs. } \\
\text { P.NP }\end{array}$ & $\begin{array}{l}\text { NP.P } \\
\text { vs. } \\
\text { iNP }\end{array}$ & $\begin{array}{c}\text { iP } \\
\text { vs. } \\
\text { P.NP }\end{array}$ & $\begin{array}{l}\text { NP.P } \\
\text { Vs. } \\
\text { iNP }\end{array}$ \\
\hline 1399134_at & LOC500054 & $\begin{array}{l}\text { similar to POT1-like telomere end- } \\
\text { binding protein }\end{array}$ & -1.13 & -1.11 & -1.13 & -1.11 & -1.07 & -1.18 & -1.13 & -1.22 & -1.06 & -1.07 & -1.10 & -1.14 \\
\hline 1386777_at & LOC500054 & $\begin{array}{l}\text { similar to POT1-like telomere end- } \\
\text { binding protein }\end{array}$ & -1.04 & -1.13 & -1.10 & -1.35 & -1.10 & -1.21 & -1.19 & -1.29 & -1.05 & -1.11 & -1.10 & -1.21 \\
\hline 1382865_at & Tsga14 & testis specific gene A14 & -1.06 & -1.09 & -1.13 & -1.06 & -1.05 & -1.06 & -1.11 & -1.10 & -1.00 & -1.14 & -1.07 & -1.09 \\
\hline 1382409_at & Tsga14 & testis specific gene A14 & -1.06 & -1.12 & -1.06 & -1.16 & -1.09 & -1.02 & -1.04 & -1.08 & -1.09 & -1.01 & -1.07 & -1.08 \\
\hline 1383828_at & Tsga13 & $\begin{array}{l}\text { EST-testis specific gene A13 } \\
\text { (predicted) }\end{array}$ & -1.25 & -1.32 & -1.45 & -1.25 & -1.19 & -1.26 & -1.57 & -1.21 & -1.26 & -1.13 & -1.34 & -1.23 \\
\hline 1369895_s_at & Podxl & podocalyxin-like & 1.04 & -1.01 & 1.00 & 1.15 & 1.05 & 1.01 & 1.04 & 1.08 & 1.03 & 1.06 & 1.03 & 1.06 \\
\hline 1378956_at & - & EST-similar to plexin A4 & 1.55 & ND & 2.16 & ND & 1.73 & 1.55 & 1.95 & 1.39 & 2.28 & ND & 1.91 & 1.41 \\
\hline 1389291_at & Chchd3 & $\begin{array}{l}\text { coiled-coil-helix-coiled-coil-helix } \\
\text { domain containing } 3\end{array}$ & -1.09 & -1.10 & -1.06 & -1.13 & -1.06 & -1.15 & -1.11 & -1.10 & -1.05 & -1.16 & -1.08 & -1.13 \\
\hline 1378824_at & - & $\begin{array}{l}\text { EST- } 4.8 \mathrm{~Kb} \text { at } 3^{\prime} \text { side of similar to } \\
\text { solute carrier family } 35 \text {, member } \\
\text { B4 }\end{array}$ & 1.06 & 1.08 & 1.09 & ND & 1.10 & 1.08 & 1.03 & 1.04 & 1.09 & ND & 1.07 & 1.10 \\
\hline 1367734_at & Akr1b1 & $\begin{array}{l}\text { aldo-keto reductase family } 1 \text {, } \\
\text { member } \mathrm{B} 1\end{array}$ & 1.12 & 1.12 & 1.22 & 1.13 & 1.27 & 1.29 & 1.16 & 1.11 & 1.25 & 1.24 & 1.20 & 1.18 \\
\hline 1395190_at & Akr1b10 & $\begin{array}{l}\text { aldo-keto reductase family } 1 \text {, } \\
\text { member B10 }\end{array}$ & 1.28 & 1.12 & 1.55 & 1.27 & 1.21 & 1.21 & 1.34 & 1.05 & 1.23 & 1.38 & 1.32 & 1.20 \\
\hline 1382034_at & Akr1b10 & $\begin{array}{l}\text { aldo-keto reductase family } 1 \text {, } \\
\text { member B10 }\end{array}$ & 1.19 & -1.02 & -1.41 & -1.08 & 1.09 & -1.16 & -1.17 & -1.05 & 1.12 & 1.12 & -1.02 & -1.04 \\
\hline 1383551_at & Bpgm & 2,3-bisphosphoglycerate mutase & 1.12 & 1.10 & 1.14 & -1.07 & 1.13 & 1.16 & 1.14 & 1.15 & 1.10 & 1.10 & 1.13 & 1.09 \\
\hline 1388544_at & Bpgm & 2,3-bisphosphoglycerate mutase & 1.09 & 1.08 & 1.10 & 1.11 & 1.11 & 1.14 & 1.10 & 1.13 & 1.08 & 1.06 & 1.10 & 1.10 \\
\hline 1390042_at & Tmem140 & transmembrane protein 140 & 1.21 & 1.32 & 1.38 & 1.24 & 1.14 & 1.13 & 1.11 & 1.14 & 1.27 & 1.06 & 1.22 & 1.18 \\
\hline 1383598_at & Wdr91 & WD repeat domain 91 (Wdr91) & 1.33 & 1.34 & 1.30 & ND & 1.47 & 1.27 & 1.50 & 1.23 & 1.46 & 1.26 & 1.41 & 1.25 \\
\hline 1378125_at & - & $\begin{array}{l}\text { EST- } 0.5 \mathrm{~Kb} \text { at } 3^{\prime} \text { side of similar to } \\
\text { HSPC049 protein }\end{array}$ & 1.32 & 1.28 & 1.46 & 1.22 & 1.35 & 1.32 & 1.42 & 1.24 & 1.42 & 1.31 & 1.40 & 1.27 \\
\hline 1373746_at & Wdr91 & WD repeat domain 91 & -1.21 & -1.09 & -1.30 & -1.14 & -1.20 & -1.13 & -1.26 & -1.14 & -1.18 & -1.23 & -1.23 & -1.14 \\
\hline 1373190_at & Cnot4 & $\begin{array}{l}\text { CCR4-NOT transcription complex, } \\
\text { subunit } 4\end{array}$ & 1.00 & 1.09 & 1.02 & 1.16 & 1.02 & 1.01 & 1.07 & 1.14 & 1.03 & 1.00 & 1.03 & 1.08 \\
\hline 1388441_at & LOC689574 & hypothetical protein LOC689574 & -1.10 & -1.03 & 1.02 & -1.06 & -1.05 & -1.13 & -1.08 & -1.10 & -1.04 & -1.09 & -1.05 & -1.08 \\
\hline 1377890_at & - & $\begin{array}{l}\text { EST- } 4.9 \mathrm{~Kb} \text { at } 3^{\prime} \text { side of solute } \\
\text { carrier family } 13 \text {, member } 4\end{array}$ & 1.17 & 1.50 & 1.22 & 1.34 & 1.16 & 1.30 & 1.14 & 1.23 & 1.19 & 1.19 & 1.18 & 1.31 \\
\hline 1392510_at & Fam180a & $\begin{array}{l}\text { family with sequence similarity } \\
\text { 180, member } A\end{array}$ & 1.22 & 1.49 & 1.78 & 1.43 & 1.13 & 1.08 & 1.15 & 1.24 & 1.08 & 1.11 & 1.25 & 1.26 \\
\hline 1391721_at & - & $\begin{array}{l}\text { EST- } 2.5 \mathrm{~Kb} \text { at } 5^{\prime} \text { side of } \\
\text { cholinergic receptor, muscarinic } 2\end{array}$ & -1.55 & ND & -2.91 & ND & -1.82 & -2.10 & -1.71 & -1.63 & -1.88 & ND & -1.92 & -1.67 \\
\hline 1379480_at & Dgki & diacylglycerol kinase, iota & 1.13 & 1.14 & 1.23 & 1.22 & 1.17 & 1.24 & 1.26 & 1.09 & 1.25 & 1.27 & 1.21 & 1.19 \\
\hline 1395107_at & Dgki & $\begin{array}{l}\text { EST-similar to diacylglycerol } \\
\text { kinase iota }\end{array}$ & -1.02 & 1.04 & -1.15 & 1.06 & 1.01 & -1.01 & 1.10 & 1.16 & -1.01 & 1.02 & -1.01 & 1.05 \\
\hline 1393410_at & - & $\begin{array}{l}\text { EST- } 0.79 \mathrm{~Kb} \text { at } 5^{\prime} \text { side of similar to } \\
\text { contactin associated protein-like } 2 \\
\text { isoform a }\end{array}$ & 1.00 & -1.18 & 1.09 & 1.15 & -1.09 & -1.11 & 1.02 & -1.06 & 1.03 & 1.00 & 1.01 & -1.04 \\
\hline 1390393_at & - & $\begin{array}{l}\text { EST- } 5 \mathrm{~Kb} \text { at } 5^{\prime} \text { side of similar to } \\
\text { contactin associated protein-like } 2 \\
\text { isoform a }\end{array}$ & -1.08 & -1.15 & -1.01 & 1.01 & -1.16 & -1.21 & -1.03 & -1.12 & -1.03 & -1.07 & -1.06 & -1.11 \\
\hline 1370007_at & Pdia4 & $\begin{array}{l}\text { protein disulfide isomerase } \\
\text { associated } 4\end{array}$ & 1.34 & 1.24 & 1.24 & 1.10 & 1.14 & 1.19 & 1.06 & 1.12 & 1.36 & 1.14 & 1.22 & 1.16 \\
\hline 1397447_at & Zfp398 & zinc finger protein 398 & -1.04 & -1.13 & -1.08 & -1.08 & -1.04 & 1.01 & -1.04 & -1.02 & -1.06 & 1.01 & -1.05 & -1.04 \\
\hline 1380094_a_at & Zfp212 & zinc finger protein 212 & 1.22 & ND & 1.30 & ND & 1.21 & ND & 1.28 & 1.15 & 1.43 & ND & 1.29 & 1.16 \\
\hline
\end{tabular}


Table 3: Significant probe sets identified by comparison of reciprocal congenic strains (Continued)

\begin{tabular}{|c|c|c|c|c|c|c|c|c|c|c|c|c|c|c|}
\hline 1390625_at & RGD1304879 & $\begin{array}{l}\text { similar to zinc finger protein } 398 \\
\text { (zinc finger DNA binding protein } \\
\text { p52/p71) }\end{array}$ & 1.43 & 1.40 & 1.27 & 1.39 & 1.33 & 1.20 & 1.30 & 1.36 & 1.46 & 1.22 & 1.36 & 1.31 \\
\hline 1377600_at & Znf777 & zinc finger protein 777 & 1.08 & 1.10 & 1.07 & -1.00 & 1.09 & 1.12 & 1.13 & 1.08 & 1.03 & 1.10 & 1.08 & 1.08 \\
\hline 1375914_at & Krba1 & KRAB-A domain containing 1 & -1.04 & -1.07 & -1.07 & 1.04 & -1.07 & -1.02 & -1.05 & -1.14 & -1.06 & -1.12 & -1.06 & -1.06 \\
\hline 1371691_at & Rarres2 & $\begin{array}{l}\text { retinoic acid receptor responder } \\
\text { (tazarotene induced) } 2\end{array}$ & -1.14 & -1.01 & 1.12 & -1.09 & -1.16 & -1.22 & -1.23 & -1.19 & -1.01 & -1.08 & -1.08 & -1.11 \\
\hline 1376401_at & RGD1561107 & EST-replication initiator 1 & 1.12 & 1.10 & 1.16 & 1.13 & 1.19 & 1.12 & 1.13 & 1.13 & 1.18 & 1.14 & 1.15 & 1.12 \\
\hline 1382755_at & Tra2a & rranscribed locus & 1.11 & 1.16 & -1.13 & -1.12 & 1.07 & 1.20 & 1.13 & 1.32 & 1.11 & 1.43 & 1.06 & 1.19 \\
\hline 1387154_at & Npy & neuropeptide $Y$ & -1.04 & -1.19 & -1.06 & 1.12 & -1.11 & -1.11 & -1.09 & -1.14 & -1.08 & -1.05 & -1.08 & -1.07 \\
\hline 1380062_at & Mpp6 & $\begin{array}{l}\text { membrane protein, palmitoylated } \\
6 \text { (MAGUK p55 subfamily } \\
\text { member } 6 \text { ) }\end{array}$ & 1.02 & 1.00 & 1.03 & -1.09 & 1.07 & 1.04 & 1.13 & 1.19 & 1.06 & 1.02 & 1.06 & 1.03 \\
\hline 1383324_at & Mpp6 & $\begin{array}{l}\text { membrane protein, palmitoylated } \\
6 \text { (MAGUK p55 subfamily } \\
\text { member 6) }\end{array}$ & 1.01 & 1.09 & 1.10 & -1.01 & 1.11 & 1.12 & 1.10 & 1.20 & 1.06 & 1.09 & 1.07 & 1.10 \\
\hline 1397419_at & Mpp6 & $\begin{array}{l}\text { membrane protein, palmitoylated } \\
6 \text { (MAGUK p55 subfamily } \\
\text { member } 6 \text { ) }\end{array}$ & -1.02 & 1.12 & 1.12 & 1.01 & 1.18 & 1.13 & 1.14 & 1.22 & 1.07 & 1.10 & 1.09 & 1.11 \\
\hline 1397949_at & - & $\begin{array}{l}\text { EST-similar to MAGUK p55 } \\
\text { subfamily member } 6\end{array}$ & -1.00 & 1.13 & 1.16 & 1.06 & 1.15 & 1.18 & 1.15 & 1.20 & 1.07 & 1.12 & 1.10 & 1.14 \\
\hline 1398627_at & - & $\begin{array}{l}\text { EST- similar to MAGUK p55 } \\
\text { subfamily member } 6\end{array}$ & -1.01 & 1.04 & 1.05 & 1.10 & 1.09 & 1.09 & 1.07 & 1.16 & 1.04 & 1.02 & 1.05 & 1.08 \\
\hline 1384136_at & Osbpl3 & oxysterol binding protein-like 3 & -1.06 & -1.03 & -1.09 & 1.07 & -1.15 & -1.03 & -1.12 & -1.16 & -1.15 & -1.06 & -1.11 & -1.04 \\
\hline 1378543_at & Hnrnpa2b1 & $\begin{array}{l}\text { EST-heterogeneous nuclear } \\
\text { ribonucleoprotein A2/B1 } \\
\text { (predicted) }\end{array}$ & -1.31 & -1.23 & -1.26 & -1.18 & -1.17 & -1.35 & -1.16 & -1.16 & -1.19 & -1.25 & -1.22 & -1.23 \\
\hline 1371395_at & $\mathrm{Cb} \times 3$ & $\begin{array}{l}\text { chromobox homolog } 3 \text { (HP1 } \\
\text { gamma homolog, Drosophila) }\end{array}$ & -1.07 & -1.07 & -1.04 & -1.00 & -1.04 & -1.02 & -1.03 & -1.03 & -1.05 & -1.10 & -1.04 & -1.04 \\
\hline 1379275_at & $\operatorname{Sn} \times 10$ & sorting nexin 10 & 2.18 & 1.40 & 1.67 & -1.05 & 1.94 & 1.58 & 1.69 & 1.58 & 2.02 & 1.55 & 1.89 & 1.39 \\
\hline 1383585_s_at & $\operatorname{Sn} \times 10$ & EST-sorting nexin 10 & -1.10 & -1.17 & -1.08 & -1.05 & -1.12 & -1.09 & -1.06 & -1.03 & -1.08 & -1.26 & -1.09 & -1.12 \\
\hline 1377198_at & - & $\begin{array}{l}\text { EST-2 Kb at } 3^{\prime} \text { side of src family } \\
\text { associated phosphoprotein } 2\end{array}$ & -1.23 & -1.33 & -1.16 & -1.09 & -1.10 & -1.09 & -1.10 & -1.19 & -1.03 & -1.15 & -1.12 & -1.17 \\
\hline 1369979_at & Skap2 & $\begin{array}{l}\text { src family associated } \\
\text { phosphoprotein } 2\end{array}$ & -1.20 & -1.22 & -1.11 & -1.04 & -1.03 & -1.16 & -1.05 & -1.07 & 1.01 & -1.12 & -1.07 & -1.12 \\
\hline 1388118_at & Hibadh & $\begin{array}{l}\text { 3-hydroxyisobutyrate } \\
\text { dehydrogenase }\end{array}$ & -1.07 & -1.01 & -1.01 & -1.04 & -1.05 & -1.09 & -1.05 & -1.03 & -1.06 & -1.05 & -1.05 & -1.04 \\
\hline 1378742_at & LOC682099 & $\begin{array}{l}\text { EST-similar to juxtaposed with } \\
\text { another zinc finger protein } 1\end{array}$ & 2.05 & 1.64 & 1.92 & 1.80 & 2.11 & 1.71 & 1.85 & 1.76 & 1.83 & 1.43 & 1.95 & 1.66 \\
\hline 1379629_at & - & $\begin{array}{l}\text { EST-4.7 kb at } 5^{\prime} \text { side of similar to } \\
\text { CAMP responsive element } \\
\text { binding protein } 5 \text { isoform alpha }\end{array}$ & -1.38 & -1.35 & -1.40 & -1.37 & -1.34 & -1.27 & -1.42 & -1.20 & -1.41 & -1.34 & -1.39 & -1.30 \\
\hline 1394833_at & - & $\begin{array}{l}\text { EST- } 0.6 \mathrm{~Kb} \text { at } 5^{\prime} \text { side of beta } \\
\text { chimerin }\end{array}$ & -1.12 & -1.15 & -1.04 & -1.19 & -1.08 & 1.02 & -1.06 & -1.10 & 1.08 & -1.03 & -1.04 & -1.09 \\
\hline 1370648_a_at & Wipf3 & $\begin{array}{l}\text { WASMASL interacting protein } \\
\text { family, member } 3\end{array}$ & 1.01 & 1.18 & -1.01 & 1.00 & -1.01 & 1.09 & 1.00 & -1.10 & 1.11 & 1.12 & 1.02 & 1.06 \\
\hline 1392541_at & Ggct & gamma-glutamyl cyclotransferase & -1.34 & -1.19 & -1.28 & -1.06 & -1.26 & -1.26 & -1.18 & -1.08 & -1.33 & -1.26 & -1.28 & -1.16 \\
\hline 1398107_at & Ggct & gamma-glutamyl cyclotransferase & -1.10 & -1.15 & -1.02 & 1.14 & -1.17 & ND & -1.06 & -1.07 & -1.15 & -1.00 & -1.10 & -1.03 \\
\hline 1394973_at & Pde1c & $\begin{array}{l}\text { EST-cyclic nucleotide } \\
\text { phosphodiesterase } 1 \mathrm{C}\end{array}$ & 1.14 & -1.01 & 1.08 & 1.09 & 1.02 & 1.02 & -1.02 & -1.01 & 1.37 & 1.16 & 1.11 & 1.05 \\
\hline 1375640_at & Fkbp9 & FK506 binding protein 9 & -1.05 & 1.28 & 1.23 & 1.01 & 1.15 & 1.04 & 1.02 & 1.01 & 1.07 & 1.05 & 1.08 & 1.07 \\
\hline 1388493_at & Ecop & $\begin{array}{l}\text { EGFR-coamplified and } \\
\text { overexpressed protein }\end{array}$ & -1.05 & -1.10 & -1.04 & -1.00 & -1.10 & -1.09 & -1.05 & -1.05 & -1.11 & -1.09 & -1.07 & -1.06 \\
\hline 1396215_at & - & $\begin{array}{l}\text { EST-similar to RIKEN cDNA } \\
2610022 \mathrm{G} 08\end{array}$ & 1.01 & -1.07 & -1.07 & -1.10 & -1.03 & -1.07 & -1.08 & -1.07 & -1.14 & -1.20 & -1.06 & -1.10 \\
\hline 1394939_at & Ppm1k & $\begin{array}{l}\text { protein phosphatase } 1 \mathrm{~K}(\mathrm{PP} 2 \mathrm{C} \\
\text { domain containing) }\end{array}$ & -1.74 & -2.67 & -2.05 & -2.36 & -2.79 & -2.57 & -1.86 & -2.05 & -2.39 & -2.05 & -2.13 & -2.33 \\
\hline 1392921_at & Ppm1k & $\begin{array}{l}\text { Protein phosphatase } 1 \mathrm{~K}(\mathrm{PP} 2 \mathrm{C} \\
\text { domain containing) }\end{array}$ & -1.07 & -1.22 & -1.21 & -1.19 & -1.12 & -1.16 & -1.14 & -1.22 & -1.15 & -1.12 & -1.14 & -1.18 \\
\hline
\end{tabular}


Table 3: Significant probe sets identified by comparison of reciprocal congenic strains (Continued)

\begin{tabular}{|c|c|c|c|c|c|c|c|c|c|c|c|c|c|c|}
\hline 1388778_at & - & $\begin{array}{l}\text { EST-3.6 Kb at } 5^{\prime} \text { side of similar to } \\
\text { protein phosphatase } 1 \mathrm{~K} \text { (PP2C } \\
\text { domain containing) }\end{array}$ & -1.27 & -1.27 & -1.27 & -1.17 & -1.18 & -1.27 & -1.22 & -1.23 & -1.22 & -1.26 & -1.23 & -1.24 \\
\hline 1367977_at & Snca & synuclein, alpha & 1.03 & -1.08 & -1.04 & -1.11 & -1.10 & -1.09 & 1.07 & 1.03 & -1.12 & -1.12 & -1.03 & -1.07 \\
\hline 1385271_at & RGD1565731 & $\begin{array}{l}\text { EST-similar to KIAA1680 protein } \\
\text { (predicted) }\end{array}$ & -1.02 & 1.04 & -1.05 & -1.08 & -1.03 & -1.02 & -1.20 & -1.11 & -1.09 & -1.01 & -1.08 & -1.04 \\
\hline 1391945_at & - & Transcribed locus & 2.01 & 1.33 & 2.37 & 1.60 & 1.54 & 1.38 & 1.88 & 1.30 & 2.61 & 1.70 & 2.05 & 1.45 \\
\hline 1393607_at & Grid2 & $\begin{array}{l}\text { EST-glutamate receptor, } \\
\text { ionotropic, delta } 2\end{array}$ & -1.27 & -1.34 & -1.13 & 1.04 & -1.17 & -1.14 & -1.12 & -1.23 & -1.02 & -1.08 & -1.14 & -1.14 \\
\hline 1386869_at & Actg2 & $\begin{array}{l}\text { actin, gamma 2, smooth muscle, } \\
\text { enteric }\end{array}$ & 1.03 & 1.05 & 1.07 & -1.11 & 1.03 & -1.00 & -1.06 & -1.10 & -1.01 & -1.02 & 1.01 & -1.03 \\
\hline 1379610_at & - & EST & 1.19 & 1.31 & -1.00 & ND & 1.14 & 1.03 & 1.24 & 1.07 & -1.03 & ND & 1.10 & 1.06 \\
\hline 1376481_at & Adamts9 & $\begin{array}{l}\text { a disintegrin-like and } \\
\text { metalloprotease (reprolysin type) } \\
\text { with thrombospondin type } 1 \\
\text { motif, } 9\end{array}$ & 1.09 & 1.30 & 1.16 & ND & 1.22 & ND & 1.30 & 1.28 & 1.27 & ND & 1.20 & 1.18 \\
\hline 1376747_at & - & $\begin{array}{l}\text { EST, strongly similar to membrane } \\
\text { associated guanylate kinase, WW } \\
\text { and PDZ domain containing } 1 \\
\text { isoform b [Mus musculus] }\end{array}$ & -1.11 & -1.22 & 1.00 & 1.05 & -1.25 & -1.12 & 1.06 & 1.02 & -1.20 & -1.13 & -1.09 & -1.08 \\
\hline 1381871_at & NA & Transcribed locus & 1.21 & 1.20 & -1.05 & 1.90 & 1.28 & 1.49 & 1.31 & 1.42 & 1.19 & 1.08 & 1.18 & 1.39 \\
\hline 1384504_at & Magi1 & $\begin{array}{l}\text { membrane associated guanylate } \\
\text { kinase, WW and PDZ domain } \\
\text { containing } 1\end{array}$ & 1.15 & 1.05 & 1.05 & 1.41 & 1.16 & 1.20 & 1.20 & 1.08 & 1.08 & 1.17 & 1.13 & 1.17 \\
\hline 1397438_at & Magi1 & $\begin{array}{l}\text { membrane associated guanylate } \\
\text { kinase, WW and PDZ domain } \\
\text { containing } 1\end{array}$ & 1.26 & 1.01 & 1.12 & 1.09 & ND & 1.02 & 1.26 & ND & 1.17 & 1.08 & 1.18 & 1.04 \\
\hline
\end{tabular}

Comparison of iP versus P.NP (this paper) and NP.P versus iNP [47] data. Probe sets that were significant (at $P \leq 0.05$ ) with consistent direction in at least one

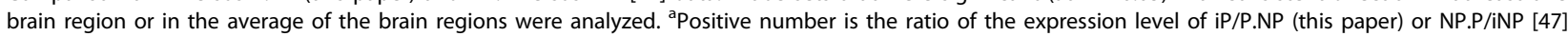
(that is, in both cases expression is higher in the strain with the $\mathrm{P}$ alleles in the introgressed region); negative numbers indicate the ratio of expression level of $\mathrm{P}$. $\mathrm{NP} / \mathrm{iP}$ (this paper) or iNP/NP.P [47]. Bold numbers indicate significant ratio of expression. ND indicates not detectable. The probe sets were sorted by genomic location; all are on chromosome 4.

In these comparisons between congenic animals, the only genes outside the chromosome 4 QTL region that are expected to show differential expression are those that are trans-regulated by genes lying within the region. Fewer trans-regulated genes showed differential expression in any one brain region, whereas analyzing the average expression values resulted in more trans-regulated genes (Table 1). However, most of these were not common to the reciprocal congenic experiment [47], suggesting that most of these trans-differences could be false positives.

Of the 74 cis-regulated candidate genes common to the reciprocal congenic experiments and the most significant trans-regulated candidate genes from the iP vs P.NP comparison, 10 genes were chosen for PCR confirmation based on their expression differences and/or literature reports of their possible involvement in pathways related to alcohol-seeking behavior. Of these, 79\% showed consistent direction of expression, in part because RT-PCR is a logarithmic process and not as good for detecting small differences in expression (Table 2). The primers for these confirmation studies, when possible, were in the coding sequences spanning an intron. It has been our experience that when primers are designed based on the coding regions, as we did here, the number of confirmed genes is lower (50 to 70\%) than when using primers designed within the 3 ' sequences used on the microarray chips (80 to $90 \%$ ), perhaps due in part to alternative splicing or 3' untranslated regions. A limitation of this confirmation was that samples were pooled by brain region, limiting the statistical power for data analysis.

Sorting nexin10 $(\operatorname{Sn} \times 10)$ is one of the most significant genes identified in both reciprocal congenics. Snx10 protein is a member of sorting nexins, a diverse group of cellular trafficking proteins that are unified by the presence of a phospholipid-binding motif, the PX domain. Snx10 protein may be involved in the regulation of endosome homeostasis [63]. In four of the brain regions we studied, the animals with the iP chromosome 4 QTL segment (iP and NP.P) demonstrated a higher expression of $S n x 10$ mRNA than those with the iNP segment (iNP and P.NP; Table 3).

Ppm1k is a serine/threonine protein phosphatase. Together with other protein kinases, these enzymes control the state of phosphorylation of cell proteins and thereby provide an important mechanism for regulating cellular activity. 


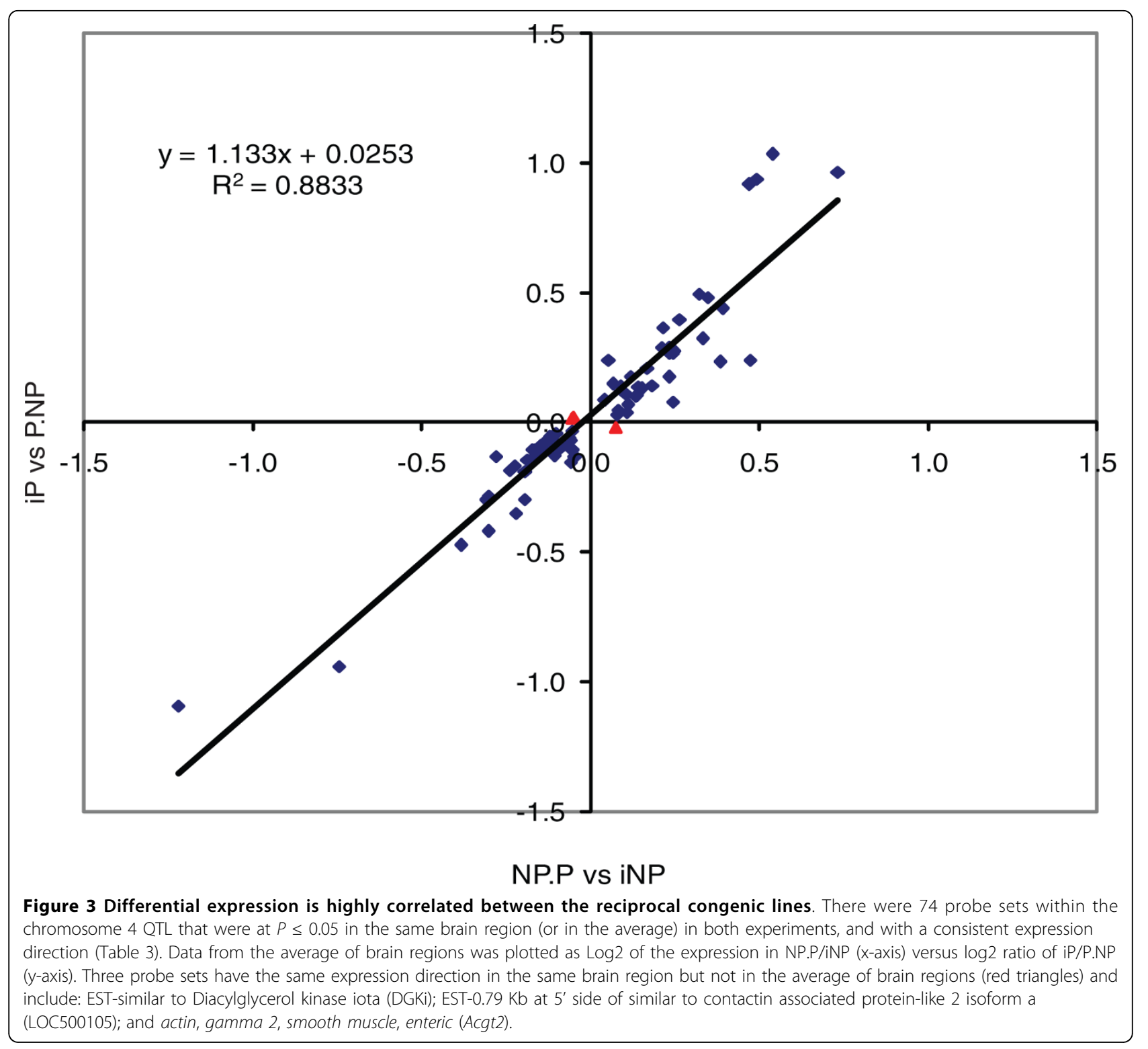

Aldo-keto reductase 1 member B1 (Akr1b1), and Akr1b10 catalyze the reduction of aliphatic and aromatic aldehydes to their corresponding alcohols. These two genes are both expressed at higher levels in the animal with the $\mathrm{P}$ chromosome 4 interval than the animal with the iNP chromosome 4 interval in both iP versus P.NP and NP.P versus iNP comparisons. Although sepiaperterin reductase (SPR) is known to be the major enzyme in the tetrahydrobiopterin (BH4) synthesis, aldo-keto reductases (AKRs) and carbonyl reductases (CBRs) can also convert 6-pyruvoyltetrahydropterin to BH4 [64-66], which is an essential cofactor for tyrosine hydroxylase $(\mathrm{TH})$ and tryptophan hydroxylase (TPH), both of which are involved in dopamine and serotonin biosynthesis (Figure 4). Alcohol is known to interact with the dopamine and serotonin neurotransmitter systems in the brain.

Diacylglycerol kinase (Dgki) regulates the levels of various pools of diacylglycerol (DAG), affecting DAGmediated signal transduction. We found that $D g k i$ mRNA is expressed at higher levels in animals with the iP chromosome 4 QTL interval (iP and NP.P) than those with the iNP interval (P.NP and iNP) in all the brain regions studied. Dgki mRNA has been shown to be expressed at higher levels in discrete brain regions of the alcohol accepting (AA) rats than in the alcohol nonaccepting (ANA) rats [67]. The highest mRNA expression of $D g k i$ was found in the human brain [68]. Dgki is expressed in the cytoplasm of most dorsal root ganglion neurons, through which primary afferent information 


\section{GTP \\ GTPCH}

Dihydroneopterin triphosphate

PTPS

6-Pyruvoyl-tetrahydropterin (PPH4)
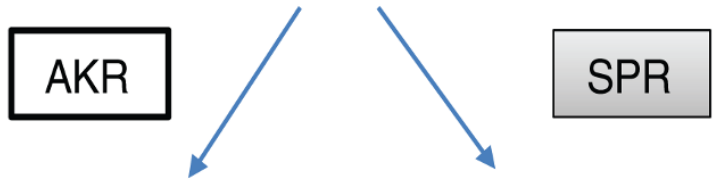

1'-OXPH4 2'-OXPH4
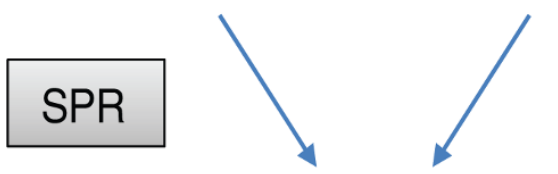

\section{AKR}

Tetrahydrobiopterin (BH4)

\section{QDPR}

q-dihydrobiopterin

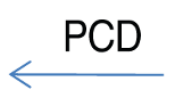

\section{$\mathrm{OH}-4 \mathrm{a}-\mathrm{BH} 4$}

Tyr

$\operatorname{Trp}$

$\operatorname{Arg}$

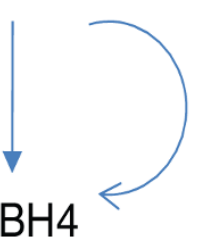

TH

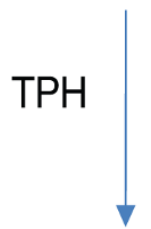

NOS

Dopamine

Serotonin $\mathrm{Cit}+\mathrm{NO}$

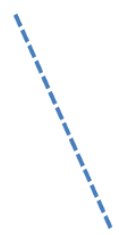

synthesis and transportation

\section{Scap2 phosphorylation Snca}

Figure 4 Candidate genes in the dopamine and serotonin system. Sepiaperterin reductase (SPR) and aldo-keto reductase (AKR) reduces an intermediate, 6-pyruvoyl-tetrahydropterin (PPH4), to 1'-OXPH4, or 2'-OXPH4, and catalyzes the final step of tetrahydrobiopterin (BH4) synthesis, an essential cofactor for phenylalanine hydroxylase, tyrosine hydroxylase (TH), tryptophan hydroxylase (TPH) and nitric oxide synthase (NOS) [65,66].

Quinoid dihydropteridine reductase (QDPR) mediates reduction of quinonoid dihydrobiopterin. Several candidate genes are related to dopamine function. Snca regulates dopamine biosynthesis and attenuates dopamine transporter activity. Scap2 phosphorylates Snca, and Copg2 is involved in the transport of the dopamine receptor 1 (D1). Arrows represent metabolic steps, and dashed lines represent genes that are functionally related. Identified candidate genes are in boxes; gray color indicates a lower expression in iP and white color indicates higher expression in iP. GTPCH, GTP-cyclohydrolase I; PTPS, 6-pyruvoyltetrahydropterin synthase; 1'-OXPH4, 1'-oxo-2'-hydroxypropyl tetrahydropterin; 2'-OXPH4, 1'-hydroxy2'-oxo-tetrahydropterin; $\mathrm{OH}-4 \mathrm{a}-\mathrm{BH} 4$, pterin-4a-carbinolamine; $\mathrm{PCD}$, pterin-4a-carbinolamine dehydratase. 
passes en route to the brain [69]. Dgki catalyzes the phosphorylation of DAG, an activator of protein kinase $\mathrm{C}$, to phosphatidic acid, and thus down-regulates second messenger pathways activated by protein kinase $C$, which play important roles in regulating behavioral responses to ethanol [70].

Protein disulfide isomerase family A, member 4 (Pdia4), also known as endoplasmic reticulum p72 (ERp72) [71], functions in disulfide bond formation and isomerization. Together with other endoplasmic reticulum-resident molecular chaperones, Pdia4 protein participates in critical steps in the folding of apolipoprotein $\mathrm{B}$ before any substantial lipidation occurs. Pdia4 mRNA was differentially expressed in four microarray gene profiling studies using animals selected for high and low alcohol consumption, which include iP versus iNP [58], inbred high-alcohol-drinking (iHAD) versus inbred lowalcohol-drinking (iLAD) (unpublished data), NP.P versus iNP [47], and iP versus P.NP (this paper). In all these studies, the animals with the high drinking allele had higher levels of Pdia4 mRNA than the animals that had the low drinking allele.

NPY is one of the most abundant neuropeptides in the central nervous system, and has been shown to have multiple functions, including regulation of feeding behavior, anxiety, addiction, bone density and memory retention [72,73]. In the present study, Npy expression has the same trend in all five brain regions, with lower expression in animals with the iP chromosome 4 QTL interval; this is consistent with previous findings of lower expression in iP than in iNP animals [43]. Alcohol consumption is inversely related to NPY levels in the brain $[43,74]$. Intracerebroventricular administration of NPY significantly decreased ethanol intake in $\mathrm{P}$ rats [75].

Snca is a previously identified candidate gene for alcohol consumption in the iP/iNP animals $[42,47]$, and has been associated with craving and alcohol dependence in humans $[31,76]$. In both microarray comparisons,Snca was found expressed at lower levels in the frontal cortex and caudate of animals with the iP QTL interval. However, an opposite trend was observed in the hippocampus, where Snca was previously shown to have higher expression in iP rats [42]. Higher mRNA and protein levels have been observed in serum from alcoholic patients compared to that from controls $[77,78]$. SNCA has been associated with craving and alcohol dependence in humans [31,76]. Skap2 and Fyn-kinase were previously identified as being involved in the phosphorylation of Snca (Figure 4). Scap 2 is expressed at lower levels in NP.P than iNP and also lower in iP than P.NP; it inhibits the phosphorylation of Snca and acts as a substrate for the Src family of kinases, such as Fyn [79]. Fyn specifically phosphorylates tyrosine residue 125 of Snca [80]. Snca and Fyn are co-localized in subcellular structures and expressed in similar brain regions [80]. Miyakawa and colleagues found that Fyn-kinase is involved in ethanol sensitivity through NMDA-receptor function [81]. Thus, these genes could work in concert to control alcohol seeking behavior.

A limitation of microarray technology is that a SNP that differs between the two strains tested could affect the hybridization to a probe set in a way that mimics an expression difference. Because expression data are composites from many probe sets, this is likely to make only a small difference. To address this possibility, individual probes within each of the 74 strong candidate probe sets were analyzed. There were no detectable SNP effects in 71 of these genes; only 3 genes had one probe that differed from the overall pattern (data not shown). This indicated that the majority of expression differences detected in this study were not the result of SNP effects.

Ingenuity Pathways Analysis (Ingenuity Systems, Inc., Mountain View, CA, USA) of the genes significant in either experiment (iP versus P. NP or NP.P versus iNP, at FDR $<0.25)$ was performed. The dopamine and serotonin biosynthesis and other pathways - for example, the Nfkb1 pathway - were overrepresented. Six candidate genes, including Akr1b1, Qdpr, Snca, Spr, Scap2, and Copg2, are directly or indirectly involved with the dopamine and serotonin biosynthesis pathway (Figure 4). Confirmation of candidate genes in the Nfkb1 pathway, which is associated with alcohol dependence [26], is ongoing.

\section{Conclusions}

Two independent gene profiling experiments using reciprocal congenic strains have identified strong, cis-acting candidate genes for alcohol consumption within the chromosome 4 QTL region. These findings provide important candidate genes for future functional and knockout studies.

\section{Materials and methods Animals}

Creation of the P.NP-(D4Rat119 (62.8 Mb)-D4Rat55 $(127.9 \mathrm{Mb})$ congenic strain has been previously described [44]. Briefly, it was initiated by crossing one male rat from the iNP strain with one female rat from the iP strain to create iP $\times$ iNP F1 animals, which were backcrossed to the iP strain to produce the N2 generation. Ten generations of backcrossing to the iP strain were performed, followed by an intercross between N10 animals to produce homozygous animals (N10F1), which resulted in the finished congenic P.NP strain (Figure 1). 
Presence of the chromosome 4 interval was confirmed using four to five microsatellite markers, including D4Rat119 and D4Rat55. Microsatelitte markers at 47.8 $\mathrm{Mb}$ (D4Rat15) and 159.3 Mb (D4Rat192) defined the extent of the introgressed region for both the P.NP and the NP.P congenic strains. At microsatelitte markers $62.8 \mathrm{Mb}$ (D4Rat119) and 127.9 Mb (D4Rat55), the NP.P strain was homozygous for the iP allele and the P.NP strain was homozygous for the iNP allele. Although the locations of the recombination boundaries have not been resolved, they are between $62.8 \mathrm{Mb}$ and $47.8 \mathrm{Mb}$ and between 127.9 $\mathrm{Mb}$ and 159.3 Mb [44]. The QTL map in Figure 2 was generated using our published data [51] plus additional markers using MAPMAKER/EXP82; the 95\% confidence interval was calculated [83] and it spans $54.8 \mathrm{Mb}$ to $105 \mathrm{Mb}$.

All animal housing and handing was as previously described [47]. The animals used in these experiments were maintained in facilities fully accredited by the Association for the Assessment and Accreditation of Laboratory Animal Care (AAALAC). All research protocols were approved by the Institutional Animal Care and Use Committee and are in accordance with the guidelines of the Institutional Animal Care and Use Committee of the National Institute on Drug Abuse, $\mathrm{NIH}$, and the Guide for the Care and Use of Laboratory Animals (Institute of Laboratory Animal Resources, Commission on Life Sciences, National Research Council 1996).

A total of 16 (8 iP and 8 P.NP) male rats, 14 to 15 weeks of age, were sacrificed by decapitation between 0900 and 1000 hours over two consecutive days, with equal numbers of animals from each strain sacrificed each day. The head was immediately immersed in chilled isopentane $\left(-50^{\circ} \mathrm{C}\right)$ for 15 seconds and then placed in a cold box maintained at $-15^{\circ} \mathrm{C}$, where the brain was rapidly removed and placed on a glass plate for dissection. All equipment used to obtain tissue was treated with RNaseZap (Ambion, Inc. Austin, TX, USA) to prevent RNA degradation. The amygdala, nucleus accumbens, caudate putamen, frontal cortex, and hippocampus were dissected as previously described [84].

\section{RNA isolation}

Dissected tissues were immediately homogenized in Trizol reagent (Invitrogen, Carlsbad, CA, USA) and processed according to the manufacturer's protocol, but with triple the suggested ratio of Trizol to tissue [60]. RNA was further purified through $\mathrm{RNeasy}^{\oplus}$ mini columns (Qiagen, Valencia, CA, USA), according to the manufacturer's protocol. To avoid genomic DNA contamination in the real-time PCR assay, the RNA was treated with DNase I. Total RNA yields from the iP and P.NP groups were similar $(P>0.4)$. The quality of the
RNA from all rats and regions was similar, as monitored by absorbance spectra from 210 to $350 \mathrm{~nm}$, by electrophoresis on $1 \%$ agarose gels, and using the Agilent Bioanalyzer to confirm the ribosomal bands.

\section{RNA labeling and microarray hybridization}

RNA from each brain region of each individual rat was labeled and hybridized separately on an Affymetrix Rat Genome 2302.0 microarray. Starting with $5 \mu \mathrm{g}$ of total RNA from each animal, biotinylated cRNA was produced using the GeneChip ${ }^{\circledR}$ Expression 3' Amplification One-Cycle Target Labeling and Control Reagents kit according to Affymetrix standard protocol. Fragmented, biotinylated cRNA $(15 \mu \mathrm{g})$ was mixed into $300 \mu \mathrm{l}$ of hybridization cocktail, of which $200 \mu$ l was used for each hybridization. Hybridization was for 17 hours at $42^{\circ} \mathrm{C}$. Washing, staining, and scanning were carried out according to the standard protocol.

To minimize systematic errors, all stages of the experiment were balanced across phenotypes. That is, equal numbers of P.NP and iP animals were sacrificed each day, and equal numbers of RNA preparations from iP and P.NP animals were processed through the labeling, hybridization, washing and scanning protocols on each day, in different alternating orders. Whenever possible, common premixes of reagents were used.

\section{Data analysis and informatics}

Each GeneChip was scanned using an Affymetrix Model 3000 scanner and underwent image analysis using Affymetrix GCOS software. Microarray data are available from the National Center for Biotechnology Information's Gene Expression Omnibus [85,86], under series accession [GEO:GSE15415] [87]. Raw cel files were imported into the statistical programming environment $\mathrm{R}$ for further analysis with tools available from the Bioconductor Project [88]. Expression data were normalized and $\log _{2}$ transformed using the RMA method $[89,90]$ implemented in the Bioconductor package RMA.

Our primary hypothesis was that cis-regulated genes within the QTL were responsible for the strain differences; thus, to detect genes within the region that differed between the P.NP and iP rats, the probe sets that mapped to the chromosome 4 QTL region between microsatellite markers D4Rat151 and D4Rat55 that flanked the introgressed region (from 29,413,686 to $128,186,835$ bases) were analyzed using $t$-tests, calculated using the package Limma [91]. To increase power and decrease the false discovery rate [92], probe sets not reliably detected on at least one-third of the microarrays in at least one experimental group (using the Affymetrix Microarray Analysis Suite 5.0 detection call) were not analyzed [93]. For the analyses of a specific brain region, the QTL probe sets were retained if present on at least 
one-third of the microarrays for either the congenic P. NP or iP animals (number of probe sets detected ranged from 644 to 694). To detect differences in gene expression common to several regions, data from the five discrete brain regions of each animal were averaged. This reduces random technical variation from the individual extractions and labeling, and thereby provides more power to detect differences that are in the same direction in multiple regions but may fall below significance in individual regions. For the analyses of average expression level, QTL probe sets were retained if present on at least one-third of the microarrays in at least one brain region in at least one strain (690 probe sets).

Secondary analyses examined expression differences elsewhere in the genome that could arise from transacting factors within the region. For the analyses of a specific brain region, the probe sets were retained if present on at least one-third of the microarrays for either the congenic P.NP or iP animals $(21,345$ to 22,994 probe sets). For the analyses of average expression level, probe sets were retained if present on at least one-third of the microarrays in at least one brain region in at least one strain (23,050 probe sets).

\section{Comparison of reciprocal congenics}

Previously published data comparing expression in NP.P versus iNP congenics [47] were compared to the present data (iP versus P.NP) to identify probe sets that exhibited consistent expression differences between the two experiments. For both experiments we calculated the ratio of expression from the animals carrying the iP QTL region to that from the animals carrying the iNP QTL region (that is, NP.P/iNP and iP/P.NP). Thus, for both experiments, a positive ratio of expression represents higher expression in the animals with the iP chromosome 4 QTL interval (iP and NP.P), and a negative value represents lower expression in the animals with iP chromosome.

Because the earlier experiment was less powerful (comparing only six animals from each strain) and because we could use the consistency of results from the two experiments to filter out false positives, we relaxed the level of significance to $P \leq 0.05$ for this comparison to reduce false negatives. Any false positives introduced by this relaxation should not be consistent between the two independent experiments. Thus, genes that were significant in the two experiments (at $P \leq$ 0.05 ) in the same brain region or in the average of the brain regions and with consistent direction in both experiments were identified (Table 3).

\section{SNP effect analysis}

Potential chromosomal regions containing SNPs were identified using probe, as opposed to probe set, level analysis according to the method of Rostoks, Borevitz, et al. [94]. Briefly, probe level expression was extracted from individual CEL files from all five brain regions after background correction. Expression levels for individual probes were averaged within animal, across brain regions, in a manner identical to that applied to probe sets. An algorithm was applied to the probes belonging to each probe set such that overall probe set group differential expression was ascertained and then each probe's expression was corrected for this. This made it easier to identify individual probes with relatively small deviations from large overall group differential expressions. For each probe set, the differential expression of each probe was then plotted using the matplot function of Bioconductor package affyPLM $[95,96]$.

\section{Mapping of ESTs}

In order to map the genomic location of significant ESTs, sequences were obtained from the Affymetrix website [97] and aligned to the rat genome using BLAST at NCBI [98]. Probe sets that aligned within a gene were referred to by that gene name. Probe sets that aligned between genes were listed as the nearest gene with the distance noted. ESTs that aligned to multiple loci or could not be positioned on the genome were labeled as EST.

\section{Quantitative real-time PCR}

Ten genes were selected for confirmation in the five brain regions used in the microarray analysis, using qRT-PCR. Amplification primers were designed from the sequence in the coding region of the gene using Vector NTI (Invitrogen); when possible, at least one primer spanned an exon/intron boundary. qRT-PCR was carried out using SYBR Green chemistry and the ABI Prism 7300 Sequence Detection System (Applied Biosystems, Foster City, CA, USA) as previously described [47]. To correct for sample-to-sample variation, an endogenous control (glyceraldehyde 3-phosphate dehydrogenase, GAPDH) was amplified with the target and served as an internal reference to normalize the data. The average GAPDH Ct values for iP and P.NP were the same in each brain region tested, making this an appropriate control gene to normalize the expression of the candidate genes of interest. Relative quantification was performed using the standard curve method (Applied Biosystems, User Bulletin \#2) [99]. For each pooled iP and P.NP sample, eight animals were pooled by each of five brain regions and six technical replicates were performed.

\section{Ingenuity pathway analysis}

The interactions between differentially expressed genes in either comparisons (with FDR <0.25) were 
investigated using Ingenuity Pathway Analysis (IPA 5.0; Ingenuity Systems, Inc., Mountain View, CA). The differentially expressed genes were uploaded into IPA. Each gene identifier was mapped to its corresponding gene in the Ingenuity Pathway Knowledge Base, a manually curated database of interactions from literature [100]. These genes were overlaid onto a global network developed from the information contained in the Ingenuity Pathway Knowledge Base. Networks of these genes, defined as the reflection of all interactions of a given gene defined in the literature, were then algorithmically generated based on their connectivity. The interactions indicate physical association, induction/ activation or repression/inactivation of one gene product by the other, directly or through another intermediary molecule.

Additional file 1: iP-PNP supplemental tables Supplemental data of expression profiling in alcoholpreferring and non-preferring reciprocal congenic rats.

Click here for file

[http://www.biomedcentral.com/content/supplementary/gb-2010-11-2r11-S1.xls]

\begin{abstract}
Abbreviations
DAG: diacylglycerol; Dgki: diacylglycerol kinase; EST: expressed sequence tag; FDR: false discovery rate; iNP: inbred alcohol-nonpreferring; iP: inbred alcohol-preferring; Mb: million bases; NP: alcohol-nonpreferring; NP.P: congenic rat in which the iP chromosome 4 QTL interval was transferred to the iNP; P: alcohol-preferring; P.NP: congenic rat in which the iNP chromosome 4 QTL interval was transferred to the iP; qRT-PCR: quantitative real-time PCR; QTL: quantitative trait locus; RMA: robust multi-chip average; SNP: single nucleotide polymorphism.
\end{abstract}

\section{Acknowledgements}

This research was supported by National Institute on Alcohol Abuse and Alcoholism (NIAAA) grants, R01 AA010707. Microarray services were provided by the Center for Medical Genomics, which is supported in part by the Indiana Genomics Initiative at Indiana University (INGEN ${ }^{\oplus}$, which is supported in part by the Lilly Endowment, Inc.).

\section{Author details}

'Indiana University School of Medicine, Department of Medicine, IB424G, 975 West Walnut Street, Indianapolis, IN 46202, USA. ${ }^{2}$ Indiana University School of Medicine, Department of Psychiatry, PR116, Indianapolis, IN 46202, USA. ${ }^{3}$ Indiana University School of Medicine, Department of Biochemistry and Molecular Biology, 635 Barnhill Dr., Indianapolis, IN 46202, USA. "Washington University Orthopedics, Campus Box 8233, One Children's Place, Suite 4S60, St Louis, Missouri 63110, USA.

\section{Authors' contributions}

$T L, L C$ and $K M$ developed the reciprocal congenic rats, HE and JM were responsible for microarray experiments, MK and JM performed data analysis with participation from $H E$, and AC performed GRT-PCR. TL, LC, HE, JM, and MK wrote the manuscript.

\section{Competing interests}

The authors declare that they have no competing interests.

Received: 18 September 2009 Revised: 21 January 2010 Accepted: 3 February 2010 Published: 3 February 2010

\section{References}

1. Heath AC, Bucholz KK, Madden PA, Dinwiddie SH, Slutske WS, Bierut L, Statham DJ, Dunne MP, Whitfield JB, Martin NG: Genetic and environmental contributions to alcohol dependence risk in a national twin sample: consistency of findings in women and men. Psychol Med 1997, 27:1381-1396.

2. Kendler KS, Neale MC, Heath AC, Kessler RC, Eaves LJ: A twin-family study of alcoholism in women. Am J Psychiatry 1994, 151:707-715.

3. Pickens RW, Svikis DS, McGue M, Lykken DT, Heston LL, Clayton PJ: Heterogeneity in the inheritance of alcoholism. A study of male and female twins. Arch Gen Psychiatry 1991, 48:19-28.

4. Covault J, Gelernter J, Hesselbrock V, Nellissery M, Kranzler HR: Allelic and haplotypic association of GABRA2 with alcohol dependence. Am J Med Genet B Neuropsychiatr Genet. 2004, 129B:104-109.

5. Edenberg HJ, Dick DM, Xuei X, Tian H, Almasy L, Bauer LO, Crowe RR, Goate A, Hesselbrock V, Jones K, Kwon J, Li TK, Nurnberger JI Jr, O'Connor SJ, Reich T, Rice J, Schuckit MA, Porjesz B, Foroud T, Begleiter H: Variations in GABRA2, encoding the alpha 2 subunit of the GABA(A) receptor, are associated with alcohol dependence and with brain oscillations. Am J Hum Genet 2004, 74:705-714.

6. Fehr C, Sander T, Tadic A, Lenzen KP, Anghelescu I, Klawe C, Dahmen N, Schmidt LG, Szegedi A: Confirmation of association of the GABRA2 gene with alcohol dependence by subtype-specific analysis. Psychiatr Genet 2006, 16:9-17.

7. Lappalainen J, Krupitsky E, Remizov M, Pchelina S, Taraskina A, Zvartau E, Somberg LK, Covault J, Kranzler HR, Krystal JH, Gelernter J: Association between alcoholism and gamma-amino butyric acid alpha2 receptor subtype in a Russian population. Alcohol Clin Exp Res 2005, 29:493-498.

8. Enoch MA, Hodgkinson CA, Yuan Q, Albaugh B, Virkkunen M, Goldman D: GABRG1 and GABRA2 as independent predictors for alcoholism in two populations. Neuropsychopharmacology 2008, 34:1245-1254.

9. Kramer JR, Chan G, Dick DM, Kuperman S, Bucholz KK, Edenberg HJ, Polgreen LA, Hesselbrock VM, Schuckit MA, Nurnberger Jl, Kapp ES, Porjesz B, Bierut LJ: Multiple-domain predictors of problematic alcohol use in young adulthood. J Stud Alcohol Drugs 2008, 69:649-659.

10. Agrawal A, Edenberg HJ, Foroud T, Bierut LJ, Dunne G, Hinrichs AL, Nurnberger Jl, Crowe R, Kuperman S, Schuckit MA, Begleiter H, Porjesz B, Dick DM: Association of GABRA2 with drug dependence in the collaborative study of the genetics of alcoholism sample. Behav Genet 2006, 36:640-650.

11. Dick DM, Bierut L, Hinrichs A, Fox L, Bucholz KK, Kramer J, Kuperman S, Hesselbrock V, Schuckit M, Almasy L, Tischfield J, Porjesz B, Begleiter $H$, Nurnberger J Jr, Xuei X, Edenberg $\mathrm{H}$, Foroud T: The role of GABRA2 in risk for conduct disorder and alcohol and drug dependence across developmental stages. Behav Genet 2006, 36:577-590.

12. Edenberg HJ, Xuei $X$, Chen HJ, Tian H, Wetherill LF, Dick DM, Almasy L, Bierut L, Bucholz KK, Goate A, Hesselbrock V, Kuperman S, Nurnberger J, Porjesz B, Rice J, Schuckit M, Tischfield J, Begleiter H, Foroud T: Association of alcohol dehydrogenase genes with alcohol dependence: a comprehensive analysis. Hum Mol Genet 2006, 15:1539-1549.

13. Guindalini C, Scivoletto S, Ferreira RG, Breen G, Zilberman M, Peluso MA, Zatz M: Association of genetic variants in alcohol dehydrogenase 4 with alcohol dependence in Brazilian patients. Am J Psychiatry 2005, 162:1005-1007.

14. Luo X, Kranzler HR, Zuo L, Yang BZ, Lappalainen J, Gelernter J: ADH4 gene variation is associated with alcohol and drug dependence: results from family controlled and population-structured association studies. Pharmacogenet Genomics 2005, 15:755-768.

15. Luo X, Kranzler HR, Zuo L, Wang S, Blumberg HP, Gelernter J: CHRM2 gene predisposes to alcohol dependence, drug dependence and affective disorders: results from an extended case-control structured association study. Hum Mol Genet 2005, 14:2421-2434.

16. Wang JC, Hinrichs AL, Stock H, Budde J, Allen R, Bertelsen S, Kwon JM, Wu W, Dick DM, Rice J, Jones K, Nurnberger JI Jr, Tischfield J, Porjesz B, Edenberg HJ, Hesselbrock V, Crowe R, Schuckit M, Begleiter H, Reich T, Goate AM, Bierut $\sqcup$ : Evidence of common and specific genetic effects: association of the muscarinic acetylcholine receptor M2 (CHRM2) gene with alcohol dependence and major depressive syndrome. Hum Mol Genet 2004, 13:1903-1911. 
17. Ducci F, Goldman D: Genetic approaches to addiction: genes and alcohol. Addiction 2008, 103:1414-1428.

18. Edenberg $H J$, Foroud $T$ : The genetics of alcoholism: identifying specific genes through family studies. Addict Biol 2006, 11:386-396.

19. Hinrichs AL, Wang JC, Bufe B, Kwon JM, Budde J, Allen R, Bertelsen S, Evans W, Dick D, Rice J, Foroud T, Nurnberger J, Tischfield JA, Kuperman S, Crowe R, Hesselbrock V, Schuckit M, Almasy L, Porjesz B, Edenberg HJ, Begleiter $H$, Meyerhof W, Bierut $L$, Goate AM: Functional variant in a bitter-taste receptor (hTAS2R16) influences risk of alcohol dependence. Am J Hum Genet 2006, 78:103-111.

20. Wang JC, Hinrichs AL, Bertelsen S, Stock H, Budde JP, Dick DM, Bucholz KK, Rice J, Saccone N, Edenberg HJ, Hesselbrock V, Kuperman S, Schuckit MA, Bierut LJ, Goate AM: Functional variants in TAS2R38 and TAS2R16 influence alcohol consumption in high-risk families of African-American origin. Alcohol Clin Exp Res 2007, 31:209-215.

21. Xu K, Anderson TR, Neyer KM, Lamparella N, Jenkins G, Zhou Z, Yuan Q Virkkunen M, Lipsky RH: Nucleotide sequence variation within the human tyrosine kinase $B$ neurotrophin receptor gene: association with antisocial alcohol dependence. Pharmacogenomics J 2007, 7:368-379.

22. Dick DM, Edenberg HJ, Xuei X, Goate A, Kuperman S, Schuckit M, Crowe R, Smith TL, Porjesz B, Begleiter H, Foroud T: Association of GABRG3 with alcohol dependence. Alcohol Clin Exp Res 2004, 28:4-9.

23. Dick DM, Plunkett J, Wetherill LF, Xuei X, Goate A, Hesselbrock V, Schuckit M, Crowe R, Edenberg HJ, Foroud T: Association between GABRA1 and drinking behaviors in the collaborative study on the genetics of alcoholism sample. Alcohol Clin Exp Res 2006, 30:1101-1110.

24. Xuei X, Dick D, Flury-Wetherill L, Tian HJ, Agrawal A, Bierut L, Goate A, Bucholz K, Schuckit M, Nurnberger J Jr, Tischfield J, Kuperman S, Porjesz B, Begleiter H, Foroud T, Edenberg HJ: Association of the kappa-opioid system with alcohol dependence. Mol Psychiatry 2006, 11:1016-1024.

25. Edenberg HJ, Wang J, Tian H, Pochareddy S, Xuei X, Wetherill L, Goate A, Hinrichs T, Kuperman S, Nurnberger JI Jr, Schuckit M, Tischfield JA, Foroud T: A regulatory variation in OPRK1, the gene encoding the kappa-opioid receptor, is associated with alcohol dependence. Hum Mol Genet 2008, 17:1783-1789.

26. Edenberg $H J$, Xuei $X$, Wetherill LF, Bierut $L$, Bucholz K, Dick DM, Hesselbrock V, Kuperman S, Porjesz B, Schuckit MA, Tischfield JA, Almasy LA, Nurnberger $\mathrm{J} \mathrm{Jr}$, Foroud T: Association of NFKB1, which encodes a subunit of the transcription factor NF-kappaB, with alcohol dependence. Hum Mol Genet 2008, 17:963-970.

27. Dick DM, Wang JC, Plunkett J, Aliev F, Hinrichs A, Bertelsen S, Budde JP, Goldstein EL, Kaplan D, Edenberg HJ, Nurnberger J Jr, Hesselbrock V, Schuckit M, Kuperman S, Tischfield J, Porjesz B, Begleiter H, Bierut LJ, Goate A: Family-based association analyses of alcohol dependence phenotypes across DRD2 and neighboring gene ANKK1. Alcohol Clin Exp Res 2007, 31:1645-1653.

28. Dick DM, Aliev F, Wang JC, Saccone S, Hinrichs A, Bertelsen S, Budde J, Saccone N, Foroud T, Nurnberger J Jr, Xuei X, Conneally PM, Schuckit M, Almasy L, Crowe R, Kuperman S, Kramer J, Tischfield JA, Hesselbrock V, Edenberg HJ, Porjesz B, Rice JP, Bierut L, Goate A: A systematic single nucleotide polymorphism screen to fine-map alcohol dependence genes on chromosome 7 identifies association with a novel susceptibility gene ACN9. Biol Psychiatry 2008, 63:1047-1053.

29. Foroud T, Wetherill LF, Kramer J, Tischfield JA, Nurnberger JI Jr, Schuckit MA, Xuei X, Edenberg HJ: The tachykinin receptor 3 is associated with alcohol and cocaine dependence. Alcohol Clin Exp Res 2008, 32:1023-1030

30. Wang JC, Grucza R, Cruchaga C, Hinrichs AL, Bertelsen S, Budde JP, Fox L, Goldstein E, Reyes O, Saccone N, Saccone S, Xuei X, Bucholz K, Kuperman S, Nurnberger J Jr, Rice JP, Schuckit M, Tischfield J, Hesselbrock V, Porjesz B, Edenberg HJ, Bierut LJ, Goate AM: Genetic variation in the CHRNA5 gene affects mRNA levels and is associated with risk for alcohol dependence. Mol Psychiatry 2008, 14:501-510.

31. Foroud T, Wetherill LF, Liang T, Dick DM, Hesselbrock V, Kramer J, Nurnberger J, Schuckit M, Carr L, Porjesz B, Xuei X, Edenberg HJ: Association of alcohol craving with alpha-synuclein (SNCA). Alcohol Clin Exp Res 2007, 31:537-545.

32. Karvonen MK, Pesonen U, Koulu M, Niskanen L, Laakso M, Rissanen A, Dekker JM, Hart LM, Valve R, Uusitupa MI: Association of a leucine(7)-toproline(7) polymorphism in the signal peptide of neuropeptide $Y$ with high serum cholesterol and LDL cholesterol levels. Nat Med 1998, 4:1434-1437.

33. Lappalainen J, Kranzler HR, Malison R, Price LH, Van Dyck C, Rosenheck RA Cramer J, Southwick S, Charney D, Krystal J, Gelernter J: A functional neuropeptide $\mathrm{Y}$ Leu7Pro polymorphism associated with alcohol dependence in a large population sample from the United States. Arch Gen Psychiatry 2002, 59:825-831.

34. Wetherill L, Schuckit MA, Hesselbrock V, Xuei X, Liang T, Dick DM, Kramer J, Nurnberger $\mathrm{JI} \mathrm{Jr}$, Tischfield JA, Porjesz B, Edenberg HJ, Foroud T: Neuropeptide $Y$ receptor genes are associated with alcohol dependence, alcohol withdrawal phenotypes, and cocaine dependence. Alcohol Clin Exp Res 2008, 32:2031-2040.

35. Mulligan MK, Ponomarev I, Hitzemann RJ, Belknap JK, Tabakoff B, Harris RA, Crabbe JC, Blednov YA, Grahame NJ, Phillips TJ, Finn DA, Hoffman PL, lyer VR, Koob GF, Bergeson SE: Toward understanding the genetics of alcohol drinking through transcriptome meta-analysis. Proc Natl Acad Sci USA 2006, 103:6368-6373.

36. Li TK, Lumeng L, Doolittle DP, Carr LG: Molecular associations of alcoholseeking behavior in rat lines selectively bred for high and low voluntary ethanol drinking. Alcohol Alcohol Suppl 1991, 1:121-124.

37. Murphy JM, Stewart RB, Bell RL, Badia-Elder NE, Carr LG, McBride WJ, Lumeng L, Li TK: Phenotypic and genotypic characterization of the Indiana University rat lines selectively bred for high and low alcohol preference. Behav Genet 2002, 32:363-388.

38. Grisel JE, Metten P, Wenger CD, Merrill CM, Crabbe JC: Mapping of quantitative trait loci underlying ethanol metabolism in BXD recombinant inbred mouse strains. Alcohol Clin Exp Res 2002, 26:610-616.

39. Cicero T: A critique of animal analogues of alcoholism. Biochemistry and Pharmacology of Ethanol New York: Plenum PressMajchrowicz E, Noble EP 1979, 2:533-560

40. Li TK, Lumeng L, Doolittle DP: Selective breeding for alcohol preference and associated responses. Behav Genet 1993, 23:163-170.

41. Carr LG, Foroud T, Bice P, Gobbett T, Ivashina J, Edenberg H, Lumeng L, Li TK: A quantitative trait locus for alcohol consumption in selectively bred rat lines. Alcohol Clin Exp Res 1998, 22:884-887.

42. Liang T, Spence J, Liu L, Strother WN, Chang HW, Ellison JA, Lumeng L, Li TK, Foroud T, Carr LG: alpha-Synuclein maps to a quantitative trait locus for alcohol preference and is differentially expressed in alcoholpreferring and -nonpreferring rats. Proc Nat Acad Sci USA 2003, 100:4690-4695.

43. Spence JP, Liang T, Habegger K, Carr LG: Effect of polymorphism on expression of the neuropeptide $Y$ gene in inbred alcohol-preferring and -nonpreferring rats. Neuroscience 2005, 131:871-876.

44. Carr LG, Habegger K, Spence JP, Liu L, Lumeng L, Foroud T: Development of congenic rat strains for alcohol consumption derived from the alcohol-preferring and nonpreferring rats. Behav Genet 2006, 36:285-290.

45. Hitzemann R, Reed C, Malmanger B, Lawler M, Hitzemann B, Cunningham B, McWeeney S, Belknap J, Harrington C, Buck K, Phillips T, Crabbe J: On the integration of alcohol-related quantitative trait loci and gene expression analyses. Alcohol Clin Exp Res 2004, 28:1437-1448.

46. Hoffman P, Tabakoff B: Gene expression in animals with different acute responses to ethanol. Addict Biol 2005, 10:63-69.

47. Carr LG, Kimpel MW, Liang T, McClintick JN, McCall K, Morse M, Edenberg $\mathrm{HJ}$ : Identification of candidate genes for alcohol preference by expression profiling of congenic rat strains. Alcohol Clin Exp Res 2007, 31:1089-1098.

48. Bonci A, Bernardi G, Grillner P, Mercuri NB: The dopamine-containing neuron: maestro or simple musician in the orchestra of addiction? Trends Pharmacol Sci 2003, 24:172-177.

49. Maldonado R: The neurobiology of addiction. J Neural Transm Supp/ 2003, 1-14.

50. Sternby B, Barros $H$, Nilsson A: In vitro effects of ethanol on human gastric and pancreatic lipolytic activities/enzymes. Scand J Gastroenterol 1996, 31:146-153.

51. Szumlinski KK, Ary AW, Lominac KD: Homers regulate drug-induced neuroplasticity: implications for addiction. Biochem Pharmacol 2008, 75:112-133.

52. Deng Y, Wang Z, Gu S, Ji C, Ying K, Xie Y, Mao Y: Cloning and characterization of a novel human alcohol dehydrogenase gene (ADHFe1). DNA Seq 2002, 13:301-306. 
53. Valjent E, Pascoli V, Svenningsson P, Paul S, Enslen H, Corvol JC, Stipanovich A, Caboche J, Lombroso PJ, Nairn AC, Greengard P, Herve D, Girault JA: Regulation of a protein phosphatase cascade allows convergent dopamine and glutamate signals to activate ERK in the striatum. Proc Natl Acad Sci USA 2005, 102:491-496.

54. Rodd ZA, Kimpel MW, Edenberg HJ, Bell RL, Strother WN, McClintick JN, Carr LG, Liang T, McBride WJ: Differential gene expression in the nucleus accumbens with ethanol self-administration in inbred alcohol-preferring rats. Pharmacol Biochem Behav 2008, 89:481-498.

55. Treadwell JA, Singh SM: Microarray analysis of mouse brain gene expression following acute ethanol treatment. Neurochem Res 2004, 29:357-369.

56. Hwang CK, Wu X, Wang G, Kim CS, Loh HH: Mouse mu opioid receptor distal promoter transcriptional regulation by SOX proteins. J Biol Chem 2003, 278:3742-3750.

57. Wei LN, Loh HH: Regulation of opioid receptor expression. Curr Opin Pharmacol 2002, 2:69-75.

58. Kimpel MW, Strother WN, McClintick JN, Carr LG, Liang T, Edenberg HJ, McBride WJ: Functional gene expression differences between inbred alcohol-preferring and -non-preferring rats in five brain regions. Alcohol 2007, 41:95-132.

59. Rodd ZA, Bertsch BA, Strother WN, Le-Niculescu H, Balaraman Y, Hayden E, Jerome RE, Lumeng L, Nurnberger JI Jr, Edenberg HJ, McBride WJ, Niculescu AB: Candidate genes, pathways and mechanisms for alcoholism: an expanded convergent functional genomics approach. Pharmacogenomics J 2007, 7:222-256.

60. Edenberg HJ, Strother WN, McClintick JN, Tian H, Stephens M, Jerome RE, Lumeng L, Li TK, McBride WJ: Gene expression in the hippocampus of inbred alcohol-preferring and -nonpreferring rats. Genes Brain Behav 2005, 4:20-30.

61. Arlinde C, Sommer W, Bjork K, Reimers M, Hyytia P, Kiianmaa K, Heilig M: A cluster of differentially expressed signal transduction genes identified by microarray analysis in a rat genetic model of alcoholism. Pharmacogenomics J 2004, 4:208-218.

62. Worst TJ, Tan JC, Robertson DJ, Freeman WM, Hyytia P, Kiianmaa K, Vrana KE: Transcriptome analysis of frontal cortex in alcohol-preferring and nonpreferring rats. J Neurosci Res 2005, 80:529-538.

63. Qin $B$, He M, Chen $X$, Pei D: Sorting nexin 10 induces giant vacuoles in mammalian cells. J Biol Chem 2006, 281:36891-36896.

64. Milstien S, Kaufman S: Immunological studies on the participation of 6pyruvoyl tetrahydropterin (2'-oxo) reductase, an aldose reductase, in tetrahydrobiopterin biosynthesis. Biochem Biophys Res Commun 1989, 165:845-850.

65. lino T, Tabata M, Takikawa S, Sawada H, Shintaku H, Ishikura S, Hara A: Tetrahydrobiopterin is synthesized from 6-pyruvoyl-tetrahydropterin by the human aldo-keto reductase AKR1 family members. Arch Biochem Biophys 2003, 416:180-187.

66. Park YS, Heizmann CW, Wermuth B, Levine RA, Steinerstauch P, Guzman J, Blau N: Human carbonyl and aldose reductases: new catalytic functions in tetrahydrobiopterin biosynthesis. Biochem Biophys Res Commun 1991, 175:738-744.

67. Sommer W, Arlinde C, Caberlotto L, Thorsell A, Hyytia P, Heilig M: Differential expression of diacylglycerol kinase iota and L18A mRNAs in the brains of alcohol-preferring AA and alcohol-avoiding ANA rats. $\mathrm{Mol}$ Psychiatry 2001, 6:103-108, 105.

68. Ding L, Traer E, Mclntyre TM, Zimmerman GA, Prescott SM: The cloning and characterization of a novel human diacylglycerol kinase, DGKiota. Biol Chem 1998, 273:32746-32752.

69. Sasaki H, Hozumi $Y$, Hasegawa $H$, Ito T, Takagi M, Ogino T, Watanabe M, Goto K: Gene expression and localization of diacylglycerol kinase isozymes in the rat spinal cord and dorsal root ganglia. Cell Tissue Res 2006, 326:35-42.

70. Newton PM, Messing RO: Intracellular signaling pathways that regulate behavioral responses to ethanol. Pharmacol Ther 2006, 109:227-237.

71. Satoh M, Shimada A, Kashiwai A, Saga S, Hosokawa M: Differential cooperative enzymatic activities of protein disulfide isomerase family in protein folding. Cell Stress Chaperones 2005, 10:211-220.

72. Heilig M: The NPY system in stress, anxiety and depression. Neuropeptides 2004, 38:213-224.

73. Hokfelt T, Stanic D, Sanford SD, Gatlin JC, Nilsson I, Paratcha G, Ledda F, Fetissov $S$, Lindfors $C$, Herzog $H$, Johansen JE, Ubink R, Pfenninger KH: NPY and its involvement in axon guidance, neurogenesis, and feeding. Nutrition 2008, 24:860-868.

74. Caberlotto L, Thorsell A, Rimondini R, Sommer W, Hyytia P, Heilig M: Differential expression of NPY and its receptors in alcohol-preferring AA and alcohol-avoiding ANA rats. Alcohol Clin Exp Res 2001, 25:1564-1569.

75. Badia-Elder NE, Stewart RB, Powrozek TA, Roy KF, Murphy JM, Li TK: Effect of neuropeptide $\mathrm{Y}$ (NPY) on oral ethanol intake in Wistar, alcoholpreferring (P), and -nonpreferring (NP) rats. Alcohol Clin Exp Res 2001, 25:386-390.

76. Bonsch D, Lederer T, Reulbach U, Hothorn T, Kornhuber J, Bleich S: Joint analysis of the NACP-REP1 marker within the alpha synuclein gene concludes association with alcohol dependence. Hum Mol Genet 2005, 14:967-971.

77. Bonsch D, Greifenberg V, Bayerlein K, Biermann T, Reulbach U, Hillemacher T, Kornhuber J, Bleich S: Alpha-synuclein protein levels are increased in alcoholic patients and are linked to craving. Alcohol Clin Exp Res 2005, 29:763-765.

78. Bonsch D, Reulbach U, Bayerlein K, Hillemacher T, Kornhuber J, Bleich S: Elevated alpha synuclein mRNA levels are associated with craving in patients with alcoholism. Biol Psychiatry 2004, 56:984-986.

79. Takahashi T, Yamashita H, Nagano Y, Nakamura T, Ohmori H, Avraham H, Avraham S, Yasuda M, Matsumoto M: Identification and characterization of a novel Pyk2/related adhesion focal tyrosine kinase-associated protein that inhibits alpha-synuclein phosphorylation. J Biol Chem 2003, 278:42225-42233.

80. Nakamura T, Yamashita H, Takahashi T, Nakamura S: Activated Fyn phosphorylates alpha-synuclein at tyrosine residue 125. Biochem Biophys Res Commun 2001, 280:1085-1092.

81. Miyakawa T, Yagi T, Kitazawa H, Yasuda M, Kawai N, Tsuboi K, Niki H: Fynkinase as a determinant of ethanol sensitivity: relation to NMDAreceptor function. Science 1997, 278:698-701.

82. Lander ES, Green P, Abrahamson J, Barlow A, Daly MJ, Lincoln SE, Newberg LA: MAPMAKER: an interactive computer package for constructing primary genetic linkage maps of experimental and natural populations. Genomics 1987, 1:174-181.

83. Darvasi A, Soller M: A simple method to calculate resolving power and confidence interval of QTL map location. Behav Genet 1997, 27:125-132.

84. Liang T, Habegger K, Spence JP, Foroud T, Ellison JA, Lumeng L, Li TK, Carr LG: Glutathione S-transferase 8-8 expression is lower in alcoholpreferring than in alcohol-nonpreferring rats. Alcohol Clin Exp Res 2004, 28:1622-1628.

85. Barrett T, Suzek TO, Troup DB, Wilhite SE, Ngau WC, Ledoux P, Rudnev D, Lash AE, Fujibuchi W, Edgar R: NCBI GEO: mining millions of expression profiles-database and tools. Nucleic Acids Res 2005, 33:D562-566.

86. Edgar R, Domrachev M, Lash AE: Gene Expression Omnibus: NCBI gene expression and hybridization array data repository. Nucleic Acids Res 2002, 30:207-210.

87. GSE15415. http://www.ncbi.n/m.nih.gov/geo/query/acc.cgi? token=bvajpccgsqgewfy\&;acc=GSE15415.

88. Gentleman RC, Carey VJ, Bates DM, Bolstad B, Dettling M, Dudoit S, Ellis B, Gautier L, Ge Y, Gentry J, Hornik K, Hothorn T, Huber W, lacus S, Irizarry R, Leisch F, Li C, Maechler M, Rossini AJ, Sawitzki G, Smith C, Smyth G, Tierney L, Yang JY, Zhang J: Bioconductor: open software development for computational biology and bioinformatics. Genome Biol 2004, 5:R80.

89. Bolstad BM, Irizarry RA, Astrand M, Speed TP: A comparison of normalization methods for high density oligonucleotide array data based on variance and bias. Bioinformatics 2003, 19:185-193.

90. Irizarry RA, Hobbs B, Collin F, Beazer-Barclay YD, Antonellis KJ, Scherf U, Speed TP: Exploration, normalization, and summaries of high density oligonucleotide array probe level data. Biostatistics 2003, 4:249-264.

91. Smyth GK: Linear models and empirical bayes methods for assessing differential expression in microarray experiments. Stat Appl Genet Mol Biol. 2004, 3:Article3 [Epub 2004].

92. Benjamini $Y$, Hochberg $Y$ : Controlling the false discovery rate: $A$ practical and powerful approach to multiple testing. J Royal Stat Soc (B) 1995, 57:289-290.

93. McClintick JN, Edenberg HJ: Effects of filtering by Present call on analysis of microarray experiments. BMC Bioinformatics 2006, 7:49.

94. Rostoks N, Borevitz JO, Hedley PE, Russell J, Mudie S, Morris J, Cardle L, Marshall DF, Waugh R: Single-feature polymorphism discovery in the barley transcriptome. Genome Biol 2005, 6:R54. 
95. Bolstad BM, Collin F, Brettschneider J, Simpson K, Cope L, Irizarry RA,

Speed TP: Applying the software routines for quality assessment. Quality

Assessment of Affymetrix GeneChip Data in Bioinformatics and Computational Biology Solutions Using R and Bioconductor New York: SpringerGentleman R, Carey V, Huber W, Irizarry R, Dudoit S 2005, 33-47.

96. Brettschneider J, Collin F, Bolstad BM, Speed TP: Quality assessment for short oligonucleotide microarray data. Technometrics 2008, 50:241-264.

97. Affymetrix. http://www.affymetrix.com/index.affx.

98. National Center for Biotechnology Information. http://www.ncbinlm.nih. gov/.

99. Applied Biosystems. http://www.appliedbiosystems.com.

100. Ingenuity Systems. http://www.ingenuity.com/.

101. Bice P, Foroud T, Bo R, Castelluccio P, Lumeng L, Li TK, Carr LG: Genomic screen for QTLs underlying alcohol consumption in the $\mathrm{P}$ and NP rat lines. Mamm Genome 1998, 9:949-955.

doi:10.1186/gb-2010-11-2-r11

Cite this article as: Liang et al:: Candidate genes for alcohol preference identified by expression profiling in alcohol-preferring and -nonpreferring reciprocal congenic rats. Genome Biology 2010 11:R11.

\section{Submit your next manuscript to BioMed Central} and take full advantage of:

- Convenient online submission

- Thorough peer review

- No space constraints or color figure charges

- Immediate publication on acceptance

- Inclusion in PubMed, CAS, Scopus and Google Scholar

- Research which is freely available for redistribution

Submit your manuscript at www.biomedcentral.com/submit 